\title{
Further dismemberment of Discocyrtus with description of a new Amazonian genus and a new subfamily of Gonyleptidae (Opiliones, Laniatores)
}

\author{
Rafael N. CARVALHO ${ }^{1, *}$ \& Adriano B. KURY ${ }^{2}$ \\ ${ }^{1,2}$ Departamento de Invertebrados, Museu Nacional/UFRJ, Quinta da Boa Vista, \\ São Cristóvão, 20.940-040, Rio de Janeiro - RJ - BRAZIL \\ *Corresponding author: rafaelcarvalhobio@hotmail.com \\ 2Email: adrianok@gmail.com \\ ${ }^{1}$ urn:1sid:zoobank.org:author:63A9A0F0-7C99-4419-8449-7506664D4766 \\ ${ }^{2}$ urn:lsid:zoobank.org:author:60FAE1F8-87F7-4A5F-BE78-BEB25BC4F898
}

\begin{abstract}
A group of Amazonian harvestmen is recognized and described as Amazochroma gen. nov. This taxon includes Discocyrtus carvalhoi Mello-Leitão, 1941 (type species), the only species of Discocyrtus previously thought to occur in Amazonia, and Amazochroma pedroi gen. et sp. nov., described here from the Brazilian states of Acre and Rondônia. New records are added for Amazochroma carvalhoi gen. et comb. nov, expanding its distribution from the Brazilian state of Mato Grosso northwards also to Pará and Amazonas in Brazil and additionally French Guiana and Suriname. Diagnostic features of Amazochroma gen. nov. include: trichromatic pattern of legs, dry marks on the dorsal scutum and base of legs and diastema in the row of macrosetae $\mathrm{C}$ of the penis ventral plate. A morphological maximum parsimony analysis (1022 scorings; 16 taxa; 64 characters) is performed to test whether Amazochroma gen. nov. is a member of Discocyrtus and if the traditional allocation of Discocyrtus in Pachylinae is defendable. A clade is retrieved containing three groups: (1) Mitobatinae, (2) Discocyrtus and (3) a clade containing Amazochroma gen. nov., Discocyrtanus and Roeweria, here described as a new subfamily of Gonyleptidae - Roeweriinae subfam. nov. Discocyrtanus Roewer, 1929 and Roeweria Mello-Leitão, 1923 are accordingly here transferred from Pachylinae to Roeweriinae subfam. nov.
\end{abstract}

Keywords. Arachnida, Grassatores, Neotropics, Amazonia, Mitobatinae, Pachylinae.

Carvalho R.N. \& Kury A.B. 2018. Further dismemberment of Discocyrtus with description of a new Amazonian genus and a new subfamily of Gonyleptidae (Opiliones, Laniatores). European Journal of Taxonomy 393: 1-32. https://doi.org/10.5852/ejt.2018.393

\section{Introduction}

Discocyrtus Holmberg, 1878 is one of the most diverse genera of Laniatores harvestmen, counting 67 valid species (Kury 2003, 2008; Kury \& Carvalho 2016). In the last few years, the authors have been conducting a project at the Museu Nacional, Universidade Federal do Rio de Janeiro, aiming to define the boundaries of this genus. 
The current diagnosis of Discocyrtus dates from Soares \& Soares (1954: 245), which in turn directly reflects the "Roewerian" classification system (as nicknamed by Henriksen 1932). The use of formulaic meristic characters such as tarsal counts, and armature of scutal areas and free tergites is not capable, alone, of satisfactorily discriminating among the increasing discovered diversity of genera in Gonyleptidae. Therefore, the current composition of Discocyrtus is predictably heterogeneous.

The vast majority of species of Discocyrtus (58 valid species) has been described in the first half of the 20th century, with the meager addition of two species later in that century (by Soares \& Soares 1970 and Tavares 1981). After a long stagnant hiatus, an isolated cavernicolous species was described by Kury (2008).

Roewer $(1913 ; 1923)$ made some progress in the systematics of Gonyleptidae by reexamining most of the type material of older authors from various museums. However, compared to more recent descriptions, Roewer's are insufficient and more than that, misleading because: (1) shapes are heavily distorted, (2) spines and apophyses are either exaggerated or attenuated, (3) the male genitalia are entirely ignored and (4) females (which are somewhat armed in Discocyrtus, for example) were mistakenly reported as males.

The most prolific Brazilian authors (in Discocyrtus) that followed this inadequate style are MelloLeitão and Soares \& Soares. Out of 67 valid species of Discocyrtus, Mello-Leitão described 24; Roewer described 17 and Soares \& Soares 13. Examples of inadequate descriptions are: Discocyrtus carvalhoi (Mello-Leitão 1941, unillustrated), Discocyrtus oliverioi (H. Soares 1945, too schematic), and Discocyrtus tenuis (Roewer 1917, distorted and based on a female).

The sheer diversity of Discocyrtus was enough to intimidate revisionary tackling by opilionologists. Even the subfamilial assignment of Discocyrtus is doubtful, because Pachylinae has been repeatedly demonstrated not to be a clade (e.g., Pinto-da-Rocha 2002) and many species of Discocyrtus are closest to the Mitobatinae rather than to typical Pachylinae (Kury 1991; Pinto-da-Rocha et al. 2014).

Gradually, a monophyletic core of Discocyrtus is being recovered by the authors (ongoing project) with the removal of unconnected species and genera. Eight available generic names are currently under the synonymy of Discocyrtus, and preliminary work has shown that under a cladistic paradigm not all should stay there. Kury \& Carvalho (2016) previously removed the genus Discocyrtanus Roewer, 1929 from the synonymy of Discocyrtus, diagnosing it as a plausible monophyletic unit.

In this work, the single Amazonian species of Discocyrtus - D. carvalhoi Mello-Leitão, 1941 - is studied along with a new species, described here in the new genus Amazochroma gen. nov. (Fig. 1), which the authors hypothesize to be closely related to it. The evidence for including $D$. carvalhoi in Discocyrtus is reviewed; in particular, its similarity with Discocyrtanus and Roeweria Mello-Leitão, 1923 is investigated based on a maximum parsimony analysis of morphological characters. Also, the null hypothesis (inclusion of Discocyrtus, Discocyrtanus and Roeweria in Pachylinae) is tested.

\section{Material and methods}

Descriptions of colors use the standard names followed by the centroid code in parentheses of the 267 Color Centroids of the NBS/IBCC Color System (Jaffer 2001+) as described in Kury \& Orrico (2006). The formula for the tarsomere count, in which the distitarsi of legs I and II are indicated between parentheses was created by Avram (1968). The formula for megaspines of the pedipalpus, in which $\mathrm{I}=$ large spine and $\mathrm{i}=$ small spine, was first introduced and used one single time by Mello-Leitão (1939) (separated by points) and modified by Kury (1989), having been consistently used in Kury's format from then on by several authors. The terminology for scutum outline follows Kury \& Medrano (2016). 
The terminology for the chaetotaxy of the penis ventral plate follows Kury \& Villarreal (2015) for the macrosetae and Kury (2016) for the microsetae. The term mesotergum (Mello-Leitão 1930) refers to the roughly subrectangular region of the dorsal scutum formed by areas I to IV and circumscribed anteriorly by the scutal groove, laterally by the lateral margins and posteriorly by the area V (posterior margin of scutum). The term $d r y$ mark ("mancha seca" Kury 1991 and "dry-mark" Kury in DaSilva \& Gnaspini 2010) refers to the more external serose layer of the cuticle that forms powdery patterns in the living animal or when it dries up after removed from preserving fluid. In the diagnoses, taxa are compared to Discocyrtus testudineus representing Discocyrtus (sensu stricto), because Discocyrtus is notably a heterogeneous assemblage.

Biogeographical units used here are from the WWF Terrestrial Eco-regions of the World (names starting with "NT"; Olson et al. 2001) and Morrone's regionalization of the Neotropics ("provinces"; Morrone 2014). They are indicated by colored background areas on the maps (Figs 2,11) based on a shapefile created by Löwenberg-Neto (2014).

Scanning electron microscopy was carried out with a JEOL JSM-6390LV at the Center for Scanning Electron Microscopy of Museu Nacional/UFRJ. All measurements are in millimeters (mm).

\section{Abbreviations of the repositories cited}

MNRJ = Museu Nacional, Universidade Federal do Rio de Janeiro, Rio de Janeiro

NZCS $=$ National Zoological Collection of Suriname

UFMG $=$ Universidade Federal de Minas Gerais

\section{Abbreviations of relevant Brazilian states}

AC $=$ Acre
AM $=$ Amazonas
MT $=$ Mato Grosso
PA $=$ Pará
RO $=$ Rondônia

\section{Other abbreviations used}

\begin{tabular}{|c|c|c|}
\hline $\mathrm{AL}$ & $=$ & abdominal scutum length \\
\hline AS & $=$ & abdominal scutum \\
\hline AW & $=$ & abdominal scutum width \\
\hline CL & $=$ & carapace length \\
\hline $\mathrm{CW}$ & $=$ & carapace width \\
\hline $\mathrm{Cx}$ & $=$ & coxa \\
\hline $\mathrm{Fe}$ & $=$ & femur \\
\hline Mt & $=$ & metatarsus \\
\hline $\mathrm{Pa}$ & $=$ & patella \\
\hline $\mathrm{Ta}$ & $=$ & tarsus (appendages) \\
\hline $\mathrm{Ti}$ & $=$ & tibia \\
\hline $\operatorname{Tr}$ & $=$ & trochanter \\
\hline VP & $=$ & ventral plate (penis) \\
\hline macrosetae $\mathrm{A} 1-\mathrm{A} 3$ & $=$ & basal macrosetae of VP \\
\hline B & $=$ & ventro-basal macrosetae of VP \\
\hline $\mathrm{C} 1-\mathrm{C} 3$ & $=$ & distal macrosetae of VP \\
\hline D1 & $=$ & dorso-lateral, subdistal small setae of VP \\
\hline E1-E2 & $=$ & ventro-distal macrosetae of VP \\
\hline
\end{tabular}


Tarsal formula: numbers of tarsomeres in tarsus I to IV (Table 4), when an individual count is given, are ordered from left to right side (figures in parentheses denote number of tarsomeres only in the distitarsi I-II).

\section{Results}

\section{Phylogenetic analysis}

\section{Choice of terminals}

The primary targets of the analysis are both of the species here included in Amazochroma gen. nov. To test their monophyly we have used putative (pre-analysis suspects) close relatives such as Discocyrtanus and Roeweria (each represented by two species). We also used as ingroups the Mitobatinae and Discocyrtus s. str. (each represented by two species, including the type species). All of these terminals have at a given point been considered to be either inside Discocyrtus or Mitobatinae. Including representatives of all subfamilies of Gonyleptidae would unnecessarily burden the analysis, so we chose representatives of Pachylinae (the subfamily where Discocyrtus is formally placed, represented here by four species Acanthopachylus aculeatus (Kirby, 1819), Anoplogynus nasutus Piza, 1938, Neopachylus imaguirei Soares \& Soares, 1947 and Pachylus chilensis (Gray, 1833)), and the paradigmatic K92 (Gonyleptes horridus Kirby, 1819). The prime outgroup to root the analysis was Ampycus telifer (Butler, 1873), representing the basal Gonyleptidae or sometimes even considered a non-gonyleptid Gonyleptoidea, the Ampycinae.

\section{Maximum parsimony (MP) analysis}

The character states were tabulated in a matrix using Morphobank 3.0 (O’Leary \& Kaufman 2012). The annotated list of characters is in Table 1 . The matrix of characters states and terminals (1052 scorings; 16 taxa; 66 characters) is in Table 2. Trees were searched in TNT (Goloboff et al. 2008b) using parsimony under implied weights (Goloboff 1993) with the traditional search algorithm and TBR branch-swapping. Space was allocated for 10000 trees in memory and 10 replicates with 10000 trees each were carried out. In this study, we used a TNT script (setk.run) written by Salvador Arias to calculate the value for the concavity constant $\mathrm{k}$ which best matches our data (for details see Goloboff et al. 2008a). The script yielded a value of $\mathrm{k}=1.992188$ for our data set, which was then employed. The stability of clades was estimated by Absolute symmetric frequencies (SFq) resampling values (10000 replicates, cut $=$ 50 , change probability $=33$ ) using TNT (Goloboff et al. 2003). As a parameter of data substantiation, absolute Bremer (or branch) support, aka "decay index" (Bremer 1994) was used, also calculated by TNT. Both bootstrap and Bremer values are shown in Fig. 4.

\section{Results of the analysis}

As a result of this analysis, a new genus and a new subfamily are proposed. The two species of Amazochroma gen. nov. (Fig. 1) are medium to large gonyleptids, with a tricolored pattern (formed by black, red and strong yellow) throughout the length of the legs, dry marks extensively covering the dorsal scutum, coxae and trochanters, and a well-developed armature on the ocularium. They are distributed in the Amazonian Forest of Brazil, Suriname and French Guiana (Fig. 2). The clade formed by Amazochroma gen. nov., Discocyrtanus and Roeweria is here described as Roeweriinae subfam. nov., which is part of a more inclusive group (here nicknamed DRMN) also including the Mitobatinae, Neopachylus Roewer, 1913 and Discocyrtus.

TNT yielded a single maximum fit $(=15.073246)$ tree (characters mapped in Fig. 3, and summary of larger groups in Fig. 4). When viewed in WinClada, which is optimized in terms of steps (equal weights), instead of fit, they would have been 162 steps long, with $\mathrm{CI}=63$ and $\mathrm{RI}=73$. The two Amazonian species treated here form a clade (described below as the genus Amazochroma gen. nov.). This clade is both 
Table 1. Character descriptions and states used in the present analysis. (continued on next pages)

1. Dorsal scutum, lateral margins, color

0 dark brown, matching the mesotergum

1 yellow, with brown reticulum, matching the mesotergum

2 light brown, reticulated, contrasting with mesotergum, which has predominant uniform dark brown background

2. Legs (most markedly III-IV), trichromatic striped pattern in yellow, black and red

0 absent

1 present

3. Body and appendages, dry marks

0 absent

1 present

4. Body and appendages, dry marks, aspect

0 restricted to tip of tubercles of dorsal scutum

1 forming cruciform pattern on dorsal scutum

2 around the tubercles all over the dorsal scutum

5. Dorsal scutum of male, outline, shape

0 alpha-shape

1 gamma-shape

2 lambda-shape

3 gamma triangular shape

4 kappa-shape

6. Ocularium, height

0 low

1 elevated

7. Ocularium, armature, type

0 pair of paramedian blunt spines tilted forwards

1 single spine or acuminate tubercle

2 one pair of very small tubercles

3 one pair of highly divergent acuminate spines

8. Ocularium, armature, inclination in lateral view in relation to body axis

0 erect (90 degrees)

1 slightly inclined anteriorly

2 greatly inclined anteriorly

\section{Ocularium, form in anterior view}

0 convex

1 saddle-shaped, with a median depression

2 subrectangular

10. Ocularium, position on the carapace in relationship to the insertion of legs

0 at second pair of legs

1 between the second and third pairs of legs

2 at third pair of legs 


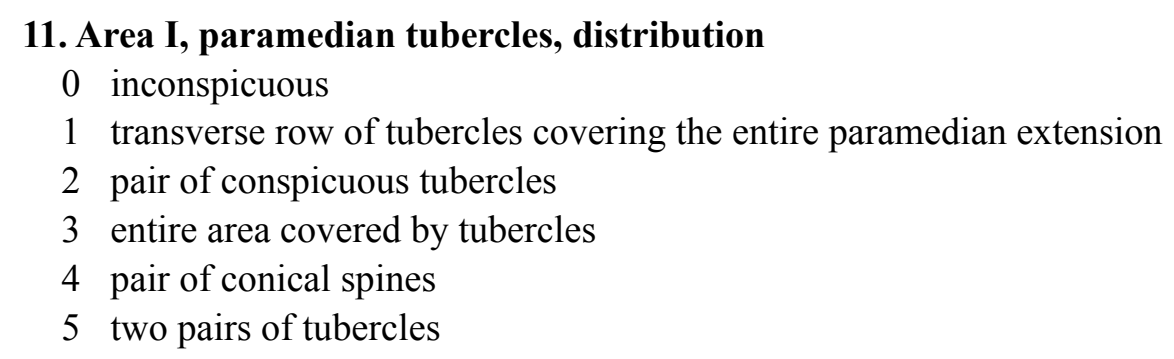

\section{Area II, paramedian tubercles, distribution}

0 inconspicuous

1 transverse row covering the entire paramedian extension

2 two anterior and six posterior

3 four anterior and four posterior

\section{Scutal area II, anterior outline}

0 fully transversal

1 gently projected in the middle, so that area II enters only slightly into area I

\section{Scutal area III, anterior outline}

0 gently arched, so that area III enters only slightly into area II

1 strongly arched, so that area III is deeply encased in area II

\section{Scutal area III, posterior outline}

0 only slightly arched

1 twice (on left and right sides) strongly convex, penetrating into area IV

16. Area III, highlighted tubercles between paramedian tubercles

0 absent

1 present

17. Area III, highlighted tubercles between paramedian tubercles, number

0 one pair

1 two pairs

\section{Area III, posterior regular transverse row of tubercles}
0 absent
1 present

\section{Scutal area III, aspect}

0 with only very small granules

1 pair of blunt or rounded, paramedian tubercles

2 pair of high, paramedian spines

\section{Scutal area IV, transverse division}

0 entire, undivided

1 divided into left and right halves by longitudinal groove

\section{Scutal area $V$, anterior outline}

0 substraight

1 gently arched, so that area III enters only slightly into area II

\section{Cx pedipalpus, disto-basal spines}
0 absent
1 present 
23. Cx pedipalpus, disto-basal spines, number

0 one

1 two

24. Fe pedipalpus, ventral row of spines

0 absent

1 present

25. Fe pedipalpus, ventral row, number of spines

0 one

1 two

2 three or more spines

26. Cx I, anterior ventral pattern of spines

0 row of spines without intervals

1 row of spines with regular intervals

27. Cx II, antero-dorsal apophysis composition

0 simple

1 bifid

28. Cx III, angle of insertion in dorsal scutum, in dorsal view

0 less than 90 degrees

190 degrees

29. Fe III of males, retrolateral distal spur
0 absent
1 present

30. Ti III of males, retroventral distal row of spines

0 absent

1 present

31. Cx IV of males, disposition in dorsal view

0 oblique to the body axis

1 parallel to the body axis

32. Cx IV of males, prodorsal distal apophysis, secondary branch

0 absent

1 present

33. Cx IV of males, prodorsal distal apophysis, shape

0 only a short stub

1 slender, geniculate

2 thick, curved horn

34. Cx IV of males, prodorsal distal apophysis, flange

0 bearing flange along its entire extension, that becomes a bud, giving it a bifurcate aspect

1 flange much reduced, at most restricted to basal half of apophysis

35. Cx IV of males, retrodorsal distal apophysis

0 absent

1 present

36. Cx IV of males, retrodorsal distal apophysis, shape

0 main tubercle only

1 main tubercle with a geminated tip 
37. Tr IV, shape

0 square

1 rectangular

38. Tr IV of males, prolateral medial apophysis

0 absent

1 present

39. Tr IV of males, prodorsal distal apophysis

0 absent or much attenuated

1 present, well-developed

\section{Fe IV, shaped}

0 C-shaped, dorsal concavity

1 straight

2 C-shaped, prolateral concavity

3 S-shaped, laterally sinuous

4 entirely straight, extremely long

5 S-shaped, dorsoventrally sinuous

41. Fe IV of males, distal proventral comb
0 absent
1 present

42. Fe IV of male, length dimorphism

0 no significant straightening and lengthening

1 very elongate and entirely unarmed

\section{Fe IV of males, prolateral distal spur}
0 absent
1 present

\section{Fe IV of males, retrolateral distal spur}
0 very attenuated
1 well-developed

\section{Pa IV, retroventral row of tubercles}
0 absent
1 present

46. Pa IV, proventral and retroventral row of tubercles, comparison
0 very attenuated
1 retroventral higher than proventral

2 proventral higher than retroventral

\section{Pa IV, proventral distal spur}
0 absent
1 present

48. Pa IV, proventral distal spur, size
0 attenuated
1 well-developed

49. Ventral plate of penis, basal convex format
0 absent
1 present 
50. Ventral plate of penis, distal part shape

0 U-form

1 trapezium, apical major base

2 trapezium, apical minor base

3 M-form

51. Field of type 1 microsetae of ventral plate, shape

0 field entire, occupying most of VP

1 field strongly reduced to a pair of latero-basal patches

2 field restricted to proximal third of VP

\section{Macrosetae C1-C3, aspect}

0 thick

1 slender

53. Macrosetae C1-C3, elongation

0 short

1 long

\section{Macrosetae C1-C3, longitudinal arrangement}

0 straight

1 diagonal, basal part oriented to the dorsal region

\section{Macrosetae C1-C3, insertion}

0 all placed distally, with subequal intervals between them

1 C3 set widely apart from the other $\mathrm{C}$, forming a diastema

2 all placed distally, united

\section{Macrosetae A, insertion on VP}

0 lateral

1 dorsal

\section{Glans ventral process}

0 extremely reduced or absent

1 present

58. Glans ventral process, shape

0 spiny cone

1 branch form

\section{Glans ventral process, flabellum}

0 absent

1 present

60. Glans ventral process, flabellum, shape

0 fan-shaped

1 scallop-shaped

2 hand-shaped

\section{Podium, position relative to VP}

0 VP with allometric elongation only in proximal part, so that podium lies far away from cluster of MS A-B

1 podium immensely elongate, running parallel to $\mathrm{VP}$ and reaching cluster of MS C

2 podium and VP not overlapping at all, compensated by columnar glans

3 podium with short cubic pre-podium reaching cluster MS A

4 podium very short, ending much before reaching cluster MS A, even with VP overlapped

5 podium projected distally, reaching cluster MS A-B, VP much clearly overlapping podium 


\section{Stylus, shape}

0 straight

1 sinuous

\section{Stylus, shape, angle of basal curvature}

0 less than 90 degrees

1 more than 90 degrees

290 degrees

3 more than 180 degrees

\section{Stylus, apical shape}

0 phallic, laterally compressed

1 cylindrical with rounded apex, without ornamentation

2 horseshoe-shaped, entirely covered by spines

3 larger aperture with serrate borders

\section{Stylus, medial spines}

0 absent

1 present

\section{Apical winglets of stylus}

0 absent

1 present

statistically significant $(\mathrm{SFq}=96)$ and well supported $($ Bremer $=4)$. The sister group of Amazochroma gen. nov. is the recently revalidated Discocyrtanus. The two terminals of Discocyrtanus do form a clade, but in itself this is not proof of the monophyly of this genus, because our analysis did not include three out of the five species. The clade formed by Amazochroma gen. nov. and Discocyrtanus is stable and well supported (95/5). This clade is in turn a sister group of Roeweria, forming a clade that we describe below as Roeweriinae subfam. nov. (pink clade). The Roeweriinae subfam. nov. are stable and well-supported (98/7). Our analysis also convincingly shows that neither Discocyrtus (blue clade), nor Neopachylus, nor ex-Discocyrtus (now in Discocyrtanus and Roeweria) share a special similarity with the Pachylinae (red clade), instead being more closely related to the Mitobatinae (green clade). We chose to convey this similarity by creating the denomination DRMN (yellow clade, including Discocyrtus, Roeweriinae subfam. nov., Mitobatinae and Neopachylus).

\section{Systematic accounts}

Class Arachnida Lamarck, 1801

Order Opiliones Sundevall, 1833

Suborder Laniatores Thorell, 1876

Infraorder Grassatores Kury, 2002

Superfamily Gonyleptoidea Sundevall, 1833

Family Gonyleptidae Sundevall, 1833

Roeweriinae subfam. nov. urn:1sid:zoobank.org:act:237C9E13-E34E-44BC-AD97-5B6ACFE915AC

\section{Included genera}

Amazochroma gen. nov., Discocyrtanus Roewer, 1929 and Roeweria Mello-Leitão, 1923 (type genus; revalidated by Kury 2003). Discocyrtanus and Roeweria were hitherto in Pachylinae. 
Table 2. Matrix of character states for the cladistic analysis of the Roeweriinae.

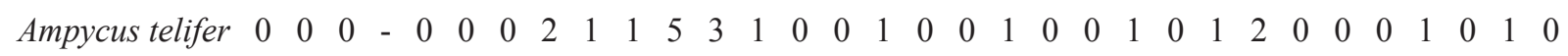
$\begin{array}{lllllllllllllllllllllllllllllllllll}0 & 0 & 0 & - & 0 & 0 & 0 & 1 & 0 & 0 & 0 & 0 & 1 & 2 & 1 & 0 & 1 & 0 & 1 & 0 & 0 & 0 & 0 & 1 & 0 & - & - & - & 0 & 1 & 0 & 0 & 0 & 0\end{array}$

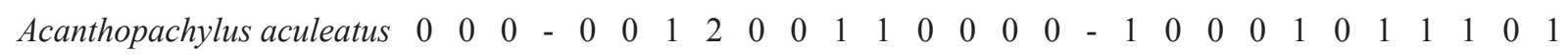
$\begin{array}{llllllllllllllllllllllllllllllllllllllllllllll}0 & 1 & 1 & 0 & 0 & 0 & 0 & - & 0 & 0 & 0 & 0 & 0 & 0 & 0 & 1 & 1 & 1 & 1 & 1 & 0 & 1 & 1 & 0 & 0 & 0 & 0 & 0 & 1 & 0 & 0 & - & 1 & 1 & 1 & 1 & 0 & 0\end{array}$

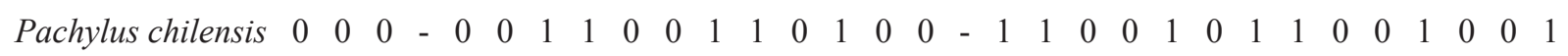
$\begin{array}{llllllllllllllllllllllllllllllllllll}0 & 2 & 0 & 0 & - & 0 & 0 & 0 & 0 & 0 & 0 & 1 & 1 & 1 & 1 & 1 & 1 & 0 & 1 & 1 & 0 & 0 & 0 & 0 & 0 & 1 & 0 & 0 & - & 1 & 1 & 1 & 1 & 0 & 0\end{array}$

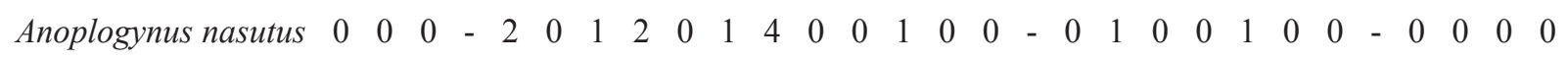
$\begin{array}{lllllllllllllllllllllllllllllllllllll}1 & 1 & 0 & 0 & 0 & 0 & - & 0 & 0 & 1 & 5 & 0 & 0 & 0 & 1 & 1 & 2 & 0 & - & 1 & 1 & 0 & 0 & 0 & 0 & 0 & 0 & 0 & - & - & - & 2 & 0 & - & 0 & 0 & 0\end{array}$

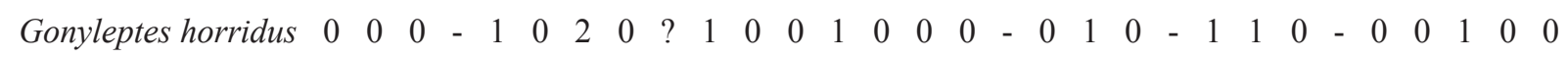
$\begin{array}{llllllllllllllllllllllllllllllllllll}1 & 1 & 1 & 0 & 0 & - & 0 & 0 & 0 & 1 & 0 & 0 & 0 & 0 & 1 & 2 & 0 & - & 1 & 0 & 0 & 0 & 0 & 0 & 2 & 0 & 1 & 1 & 1 & 0 & 3 & 1 & 3 & 1 & 0 & 0\end{array}$

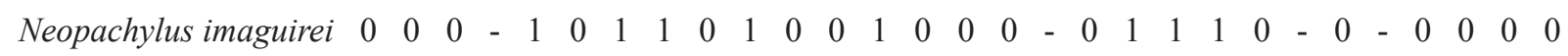
$\begin{array}{llllllllllllllllllllllllllllllllllllll}1 & 0 & 1 & 1 & 0 & 1 & 1 & 1 & 0 & 1 & 0 & 0 & 0 & 0 & 0 & 1 & 0 & 1 & 0 & 1 & 1 & 0 & 0 & 0 & 0 & 1 & 0 & 1 & 1 & 1 & 2 & 4 & 0 & - & 2 & 0 & 0\end{array}$

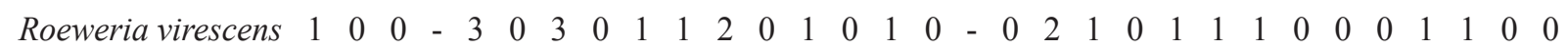
$\begin{array}{lllllllllllllllllllllllllllllllllll}0 & 2 & 1 & 1 & 0 & 1 & 0 & 0 & 1 & 0 & 0 & 0 & 0 & 1 & 2 & 1 & 0 & 0 & 2 & 2 & 1 & 1 & 0 & 1 & 1 & 0 & - & - & - & 5 & 1 & 2 & 3 & 0 & 1\end{array}$

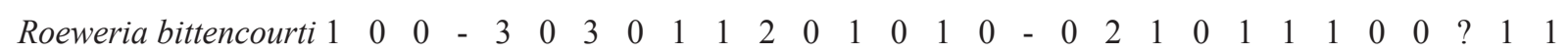
$\begin{array}{lllllllllllllllllllllllllllllllllllll}0 & 0 & 0 & 2 & 1 & 1 & 0 & 1 & 0 & 0 & 1 & 0 & 0 & 0 & 0 & 1 & 0 & 0 & - & 1 & 2 & 0 & 1 & 1 & 0 & 1 & 1 & 0 & - & - & - & 5 & 1 & 2 & 3 & 0 & 1\end{array}$

Amazochroma carvalhoi gen. et comb. nov. $00 \begin{array}{llllllllllllllllllllll} & 0 & 1 & 2 & 1 & 0 & 3 & 1 & 1 & 1 & 2 & 2 & 1 & 0 & 0 & 1 & 0 & 0 & 2 & 1 & 0 & 1\end{array}$ $\begin{array}{llllllllllllllllllllllllllllllllllllll}1 & 1 & 0 & 0 & 1 & 1 & 1 & 0 & 0 & 0 & 2 & 1 & 1 & 0 & 1 & 1 & 1 & 0 & 0 & 0 & 1 & 1 & 0 & 2 & 1 & 0 & 1 & 2 & 0 & 1 & 1 & 0 & 1 & 0 & 0 & - & -\end{array}$ - $\begin{array}{llllll}5 & 1 & 2 & 3 & 0 & 1\end{array}$

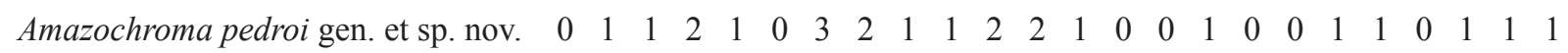
$\begin{array}{lllllllllllllllllllllllllllllllllllllllllllllll}0 & 0 & 1 & 1 & 1 & 1 & 0 & 0 & 2 & 1 & 0 & - & 0 & 1 & 1 & 0 & 0 & 0 & 1 & 1 & 0 & 2 & 1 & 0 & 1 & 2 & 0 & 1 & 1 & 0 & 1 & 0 & 0 & - & - & - & 5\end{array}$ $\begin{array}{lllll}1 & 2 & 3 & 0 & 1\end{array}$

Discocyrtanus goyazius $\quad 0 \begin{array}{llllllllllllllllllllllllllllll} & 0 & 1 & 0 & 1 & 0 & 3 & 1 & 1 & 1 & 2 & 0 & 1 & 0 & 0 & 1 & 0 & 0 & 1 & 1 & 0 & 1 & 1 & 1 & 0 & 0 & 1 & 1 & 1\end{array}$ $\begin{array}{llllllllllllllllllllllllllllllllllllll}0 & 0 & 0 & 1 & 1 & 1 & 0 & 1 & 0 & 1 & 3 & 1 & 0 & 1 & 1 & 1 & 2 & 1 & 0 & 1 & 2 & 0 & 1 & 1 & 0 & 0 & 0 & 0 & - & - & - & 5 & 1 & 2 & 3 & 0 & 1\end{array}$

Discocyrtanus oliverioi $100 \begin{array}{lllllllllllllllllllllllllllll} & 0 & 1 & 0 & 1 & 0 & 3 & 1 & 1 & 1 & 2 & 0 & 1 & 0 & 0 & 1 & 0 & 0 & 1 & 1 & 0 & 1 & 1 & 1 & 0 & 0 & ? & 1 & 1\end{array}$ $\begin{array}{llllllllllllllllllllllllllllllllllllll}0 & 0 & 0 & 1 & 1 & 1 & 0 & 1 & 0 & 1 & 3 & 1 & 0 & 1 & 1 & 1 & 2 & 1 & 0 & 1 & 2 & 0 & 1 & 1 & 0 & 0 & 0 & 0 & - & - & - & 5 & 1 & 2 & 3 & 0 & 1\end{array}$

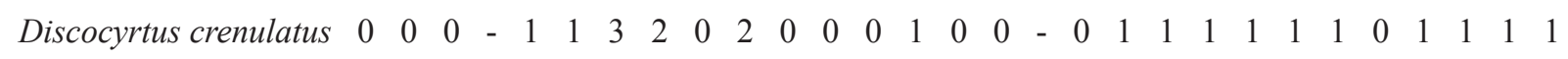

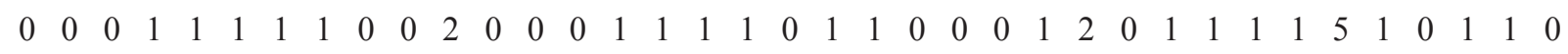

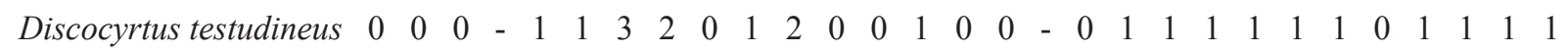
$\begin{array}{llllllllllllllllllllllllllllllllllllll}0 & 1 & 0 & 1 & 1 & 1 & 1 & 1 & 0 & 0 & 2 & 0 & 0 & 0 & 1 & 1 & 1 & 1 & 1 & 1 & 1 & 0 & 0 & 0 & 1 & 2 & 0 & 1 & 1 & 1 & 1 & 5 & 1 & 0 & 1 & 1 & 0\end{array}$

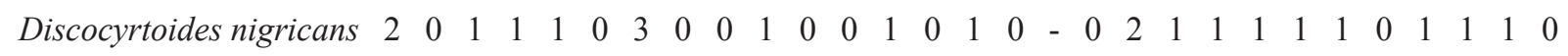
$\begin{array}{lllllllllllllllllllllllllllllllllllllll}0 & 0 & 0 & 1 & 1 & 1 & 1 & 1 & 0 & 0 & 4 & 0 & 1 & 0 & 0 & 1 & 0 & 0 & - & 1 & 1 & 0 & 0 & 0 & 1 & 2 & 0 & 1 & 1 & 1 & 1 & 5 & 1 & 0 & 1 & 1 & 0\end{array}$

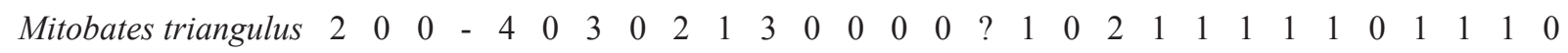
$\begin{array}{llllllllllllllllllllllllllllllllllllll}0 & 0 & 0 & - & - & 0 & - & 1 & 0 & 0 & 4 & 0 & 1 & 0 & 0 & 1 & 0 & 0 & - & 1 & 3 & 0 & 0 & 0 & 1 & 2 & 0 & 1 & 1 & 1 & 0 & 5 & 1 & 1 & 1 & 1 & 0\end{array}$ 


\section{Diagnosis}

Dry marks either around the tubercles or restricted to their tips, but in both cases all around dorsal scutum (only in Amazochroma gen. nov. and Discocyrtanus, absent in Roeweria; contrasting with Discocyrtus and some Mitobatinae [e.g., in Ischotherus Kury, 1991, Mitobates Sundevall, 1833 Neoancistrotus Mello-Leitão, 1927, Promitobates Roewer, 1913, Ruschia Mello-Leitão, 1940] where it is absent and with other Mitobatinae which possess dry marks arranged in broad stripes, often cruciform [e.g., in Discocyrtoides Mello-Leitão, 1923, Longiperna Roewer, 1929). Ocularium convex, with a median depression (contrasting with the convex form without depression in Discocyrtus and Discocyrtoides or rectangular form in Mitobates). Mesotergum divided into 4 areas (same as in Discocyrtus testudineus Holmberg, 1876 and Mitobatinae). Area I with a pair of conspicuous paramedian tubercles (same as D. testudineus, absent in D. crenulatus Roewer, 1913 and Discocyrtoides). Retrodorsal distal apophysis of Cx IV of males with only a main tubercle (absent in Amazochroma pedroi gen. et sp. nov., contrasting the form with a geminated tip present in Discocyrtus and some Mitobatinae). Distal part of the VP of penis forming a trapezium, with an apical minor base (contrasting with a trapezium with an apical major base occurring in Discocyrtus and Discocyrtoides or the M-form of Mitobates). Macrosetae C1-C3 of VP elongate and slender (contrasting with the short and thick form found in Discocyrtus and Mitobatinae). Macrosetae C1-C3 insertion with C3 set widely apart from the other C, forming a diastema (present in Amazochroma gen. nov. and Roeweria, contrasting with all macrosetae $\mathrm{C}$ placed distally with subequal intervals between them as found in Discocyrtanus and with macrosetae C placed distally, united as in Discocyrtus and Mitobatinae). Ventral of glans process extremely reduced or absent (contrasting with the presence of a stem and a flabellum in Discocyrtus and Mitobatinae). Stylus sigmoid, strongly bent to dorsal proximally and overall curved to ventral more distally (present in Amazochroma gen. nov. and Discocyrtanus, contrasting with the C-shape, overall arched to dorsal found in Roeweria and the substraight shape as in Discocyrtus and Mitobatinae). Angle of basal curvature of stylus around 90 degrees (in opposition to form with less than 90 degrees in Discocyrtus and Discocyrtoides or more than 90 degrees in Mitobates). Apical winglets of stylus (present in Amazochroma gen. nov., Discocyrtanus and Roeweria, absent in Discocyrtus and Mitobatinae).

\section{Amazochroma gen. nov. urn:1sid:zoobank.org:act:8DB19042-42A0-46BE-8A3F-3EB224861351}

\section{Type species}

Discocyrtus carvalhoi Mello-Leitão, 1941.

\section{Etymology}

From region name Amazonia + the Greek $\chi \rho \tilde{\omega} \mu \alpha$ (color), referring to the vivid bands shown by the species, contrasting with the dull color of most Amazonian gonyleptids. Gender neuter.

\section{Diagnosis}

Amazochroma gen. nov. has the outline of the male dorsal scutum gamma-shaped (in common with Discocyrtanus and D. testudineus, different from the gamma triangular shape in Roeweria). Ocularium low (in common with Discocyrtanus and Roeweria, contrasting with an elevated present in D. testudineus), with a pair of strong paramedian divergent spines (as in D. testudineus, Discocyrtanus and Roeweria). Legs with trichromatic striped pattern (most markedly III-IV) in strong yellow, red and black (not occurring in Mitobatinae, D. testudineus, Discocyrtanus and Roeweria). Area II with two anterior and six posterior paramedian tubercles (not occurring in Mitobatinae, D. testudineus, Discocyrtanus and Roeweria). Anterior outline of scutal area III only gently arched, not convex penetrating into area II (as in Discocyrtanus and Roeweria, contrasting with an outline strongly arched deeply encased in area II found in D. testudineus). Posterior outline of scutal area III only gently arched, not twice convex 

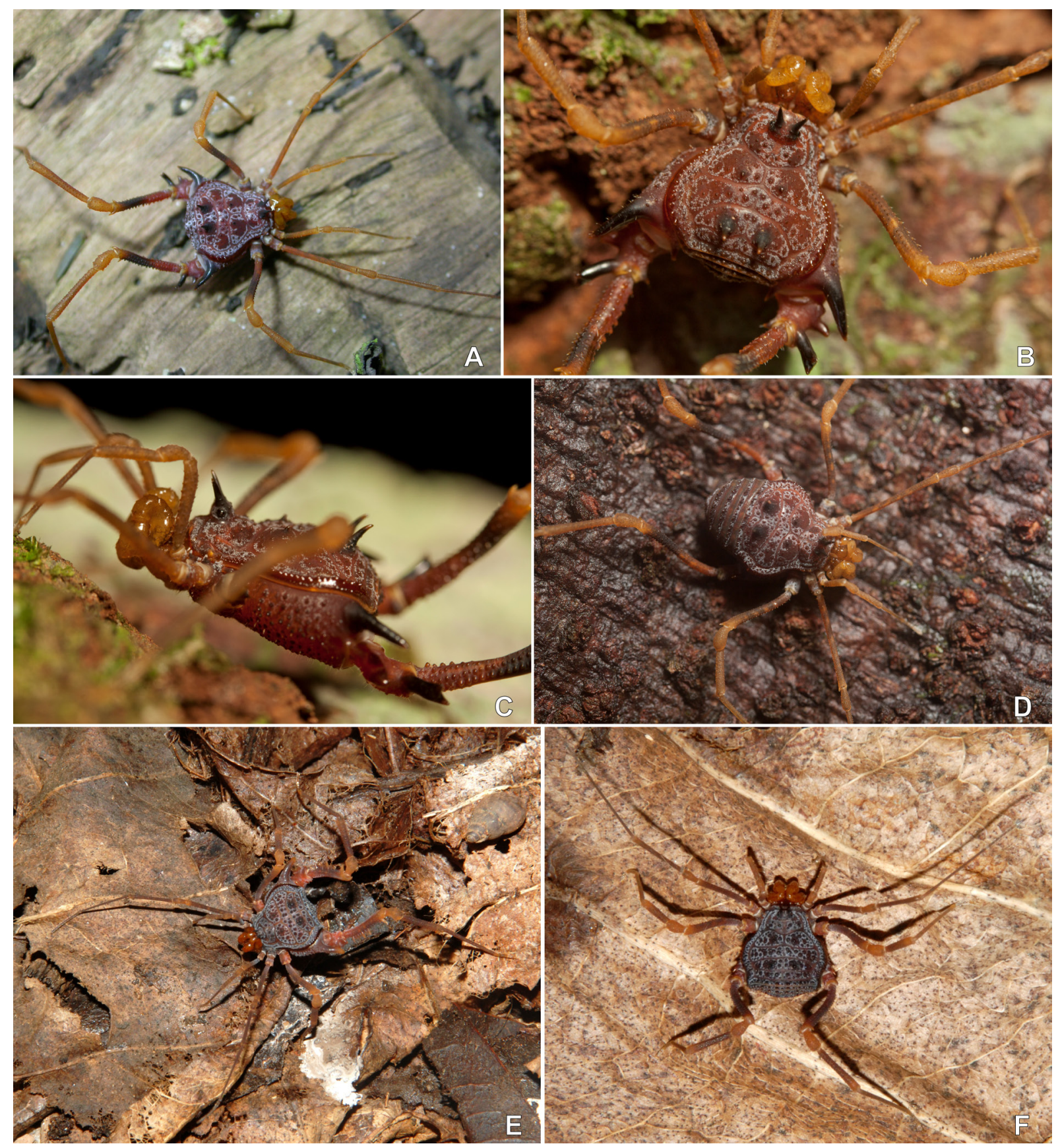

Fig. 1. Amazochroma gen. nov., specimens in vivo. A-D. Amazochroma carvalhoi (Mello-Leitão, 1941) gen. et comb. nov.: A. Ô, Brazil, Amazonas. B-C. đ, French Guiana, Maripasoula. D., , French Guiana, Maripasoula. E-F. Amazochroma pedroi gen. et sp. nov. E. ô, Brazil, Rondônia, Monte Negro. F. , Brazil, Rondônia, Porto Velho. Images courtesy of Glauco Machado (A), Sébastien Cally (B-D) and Pedro Martins (E-F). 
penetrating into area IV (in common with Discocyrtanus and D. testudineus, different from twice on left and right sides - strongly convex penetrating into area IV found in Roeweria). Tr IV with a prolateral medial apophysis (not occurring in Mitobatinae, D. testudineus, Discocyrtanus and Roeweria). Pa IV without a retroventral row of tubercles (present in Mitobatinae, D. testudineus, Discocyrtanus and Roeweria). Stylus strongly sigmoid (in common with Discocyrtanus, different from C-shaped in Roeweria and the substraight shape in D. testudineus). Stylus with well-marked apical barbed winglets (same as in Discocyrtanus and Roeweria, absent in D. testudineus). Presence of well-developed dry marks encircling the granules and tubercles of dorsal scutum, free tergites and Cx-Tr I-IV (in contrast to presence restricted to tip of tubercles of dorsal scutum in Discocyrtanus and absence in D. testudineus and Roeweria). Legs with trichromatic striped pattern (most markedly III-IV) in strong yellow, red and black (not occurring in D. testudineus, Discocyrtanus and Roeweria). Cx IV of males with prodorsal distal apophysis very strong and substraight, only gently curved to ventral side (extremely curved in Roeweria, slender geniculate in Discocyrtanus and D. testudineus). Macroseta C3 set widely apart from the other $\mathrm{C}$, forming a diastema (as in Roeweria, contrasting with all macrosetae C placed distally, with subequal intervals between them found in Discocyrtanus and macrosetae C placed distally, united as in D. testudineus).

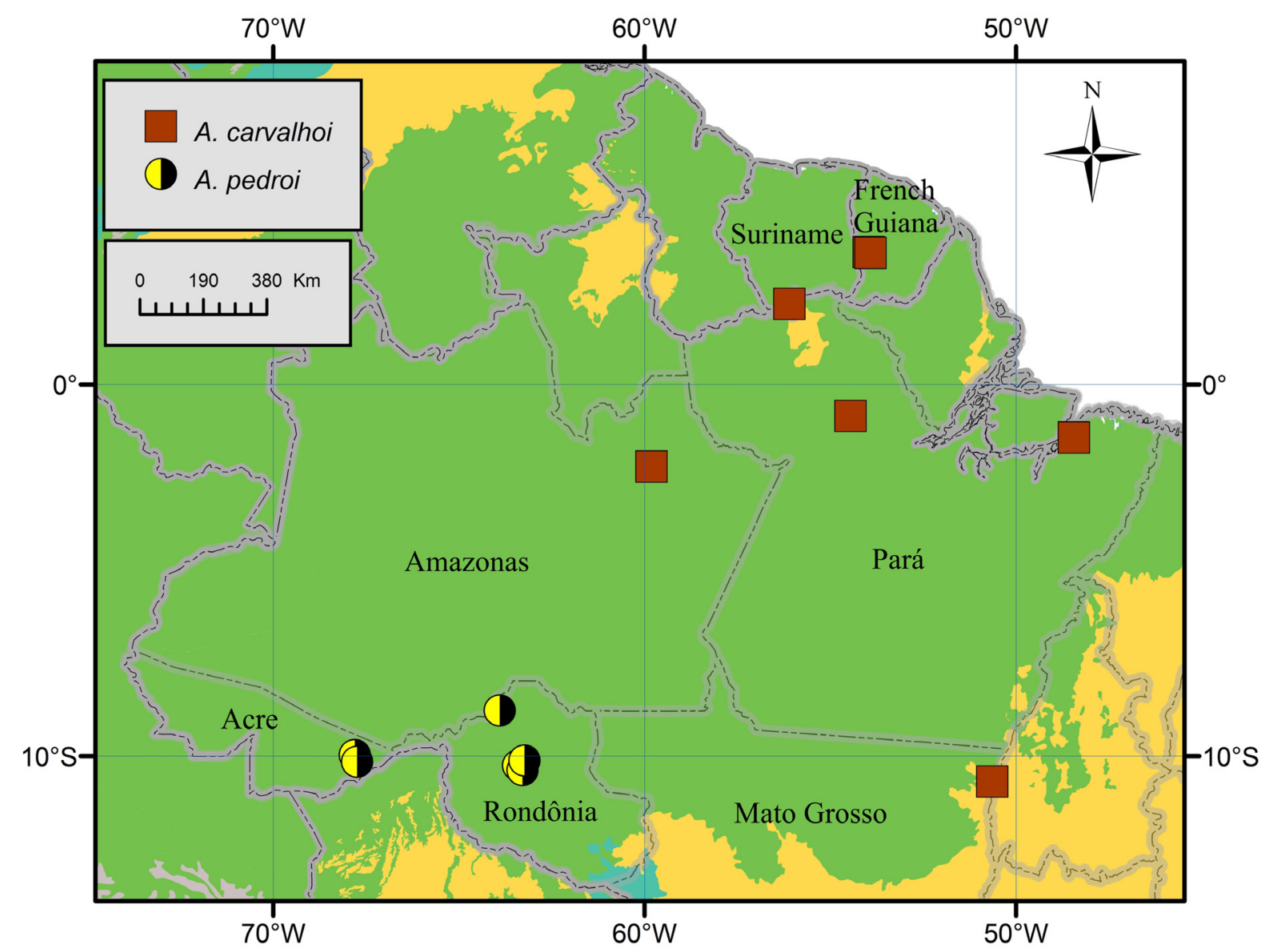

Fig. 2. Northern Brazil and Guyanas, showing distribution of the species of Amazochroma gen. nov. Shaded areas in the background are WWF biomes, green are moist broadleaf forests and orange are grasslands, savannas and shrublands. 


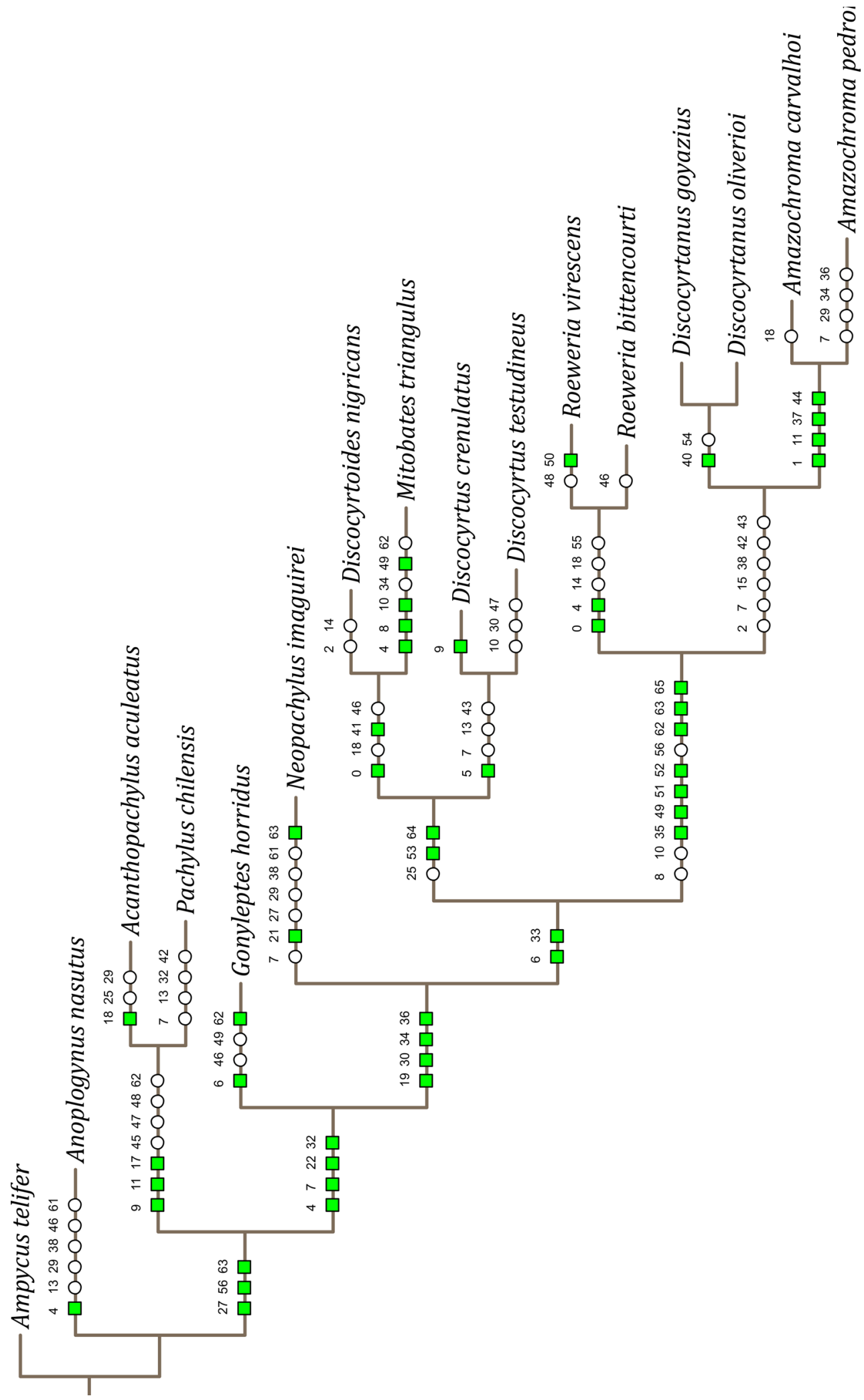

Fig. 3. Cladogram depicting proposed external and internal phylogenetic relationships of Roeweriinae subfam. nov., with unambiguous synapomorphies for each clade mapped. This is the single tree obtained by TNT. Small numbers above symbols are the numbers of the characters. Green squares = nonhomoplastic synapomorphies; white circles = homoplastic synapomorphies. 


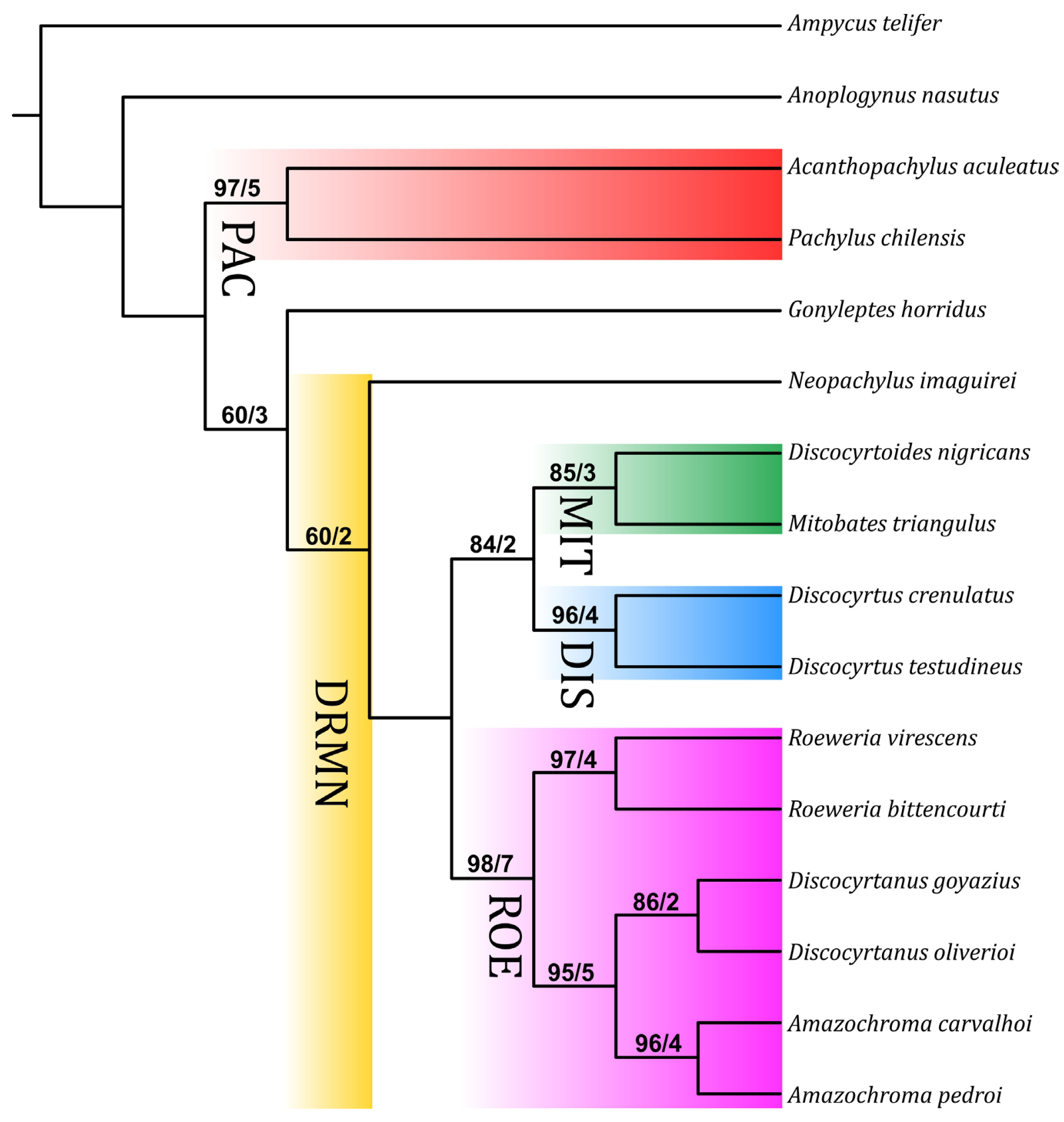

Fig. 4. Single MP tree from TNT. Numbers at branches are the stability from absolute symmetric frequencies resampling percentage values $(\mathrm{cut}=50)$ / decay index from Bremer Support. Abbreviations and colored backgrounds codes are: PAC (red) = Pachylinae; DRMN (yellow) = Monophyletic group including Discocyrtus, Roeweriinae subfam. nov., and Mitobatinae; MIT (green) = Mitobatinae; DIS (blue) $=$ Discocyrtus; ROE (magenta) $=$ Roeweriinae subfam. nov. 


\section{Included species.}

Amazochroma carvalhoi (Mello-Leitão, 1941) gen. et comb. nov. and Amazochroma pedroi gen. et sp. nov.

\section{Combined distribution.}

Brazil, states of Acre, Amazonas, Mato Grosso, Pará and Rondônia. Suriname, district of Sipaliwini. France, department of French Guiana, administrative subdivision of Maripasoula (Figs 2, 11).

Amazochroma carvalhoi (Mello-Leitão, 1941) gen. et comb. nov. Figs 1 A-D, 5-6

Discocyrtus carvalhoi Mello-Leitão, 1941: 437.

Discocyrtus carvalhoi - Soares \& Soares 1954: 247; Kury 2003: 161.

\section{Material examined}

\section{Holotype}

BRAZIL: ${ }^{\lambda}$, MT, Santa Terezinha, Barra do Tapirapé, $10.683^{\circ}$ S, $50.633^{\circ}$ W, A.L. Carvalho leg. (MNRJ 5143).

\section{Other material examined}

BRAZIL: 1 + , AM, Manaus, Reserva Florestal ZF-3, $2.21^{\circ} \mathrm{S}, 59.81^{\circ} \mathrm{W}$, Reserva do km 41, 28-31 Jul. 2002, G. Machado leg. (MNRJ 9067); 1 đ̃, 1 ㅇ, PA, Belém, Parque Ambiental de Belém (Utinga), $1.424827^{\circ} \mathrm{S}, 48.438016^{\circ} \mathrm{W}, \mathrm{Feb} .2010$, G.H.F. Azevedo et al. leg. (UFMG 9382); 1 9, PA, Monte Alegre, Instituto de Pesquisas Ecológicas da Amazônia (IPEAm), 0.84467 S, 54.45327 W, 1970, Mário leg. (MNRJ 8811).

FRANCE: $1 \overbrace{}^{\Uparrow}$, French Guiana, Arrondissement of Saint-Laurent-du-Maroni, Commune de Maripasoula, Monts Atachi Bakka, 3.54463 ${ }^{\circ}$ N, 53.91278 ${ }^{\circ}$ W, 632 m asl., 6 Feb. 2015, S. Cally leg. (MNRJ 8801); $1 \hat{\jmath}, 1$ q, French Guiana, Arrondissement of Saint-Laurent-du-Maroni, Commune de Maripasoula, Monts Atachi Bakka, 3.56714 N, 53.96177 W, 127 m asl., 8 Feb. 2015, S. Cally leg. (MNRJ 8799).

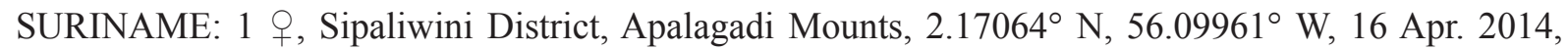
A. Fouquet and J.P. Vacher leg. (MNRJ 8800); 1 ô, Sipaliwini District, Apalagadi Mounts, $2.17064^{\circ}$ N, 56.09961 ${ }^{\circ}$ W, SR140416HC001-22, 16 Apr. 2014, A. Fouquet and J.P. Vacher leg. (NZCS); 1 운, Sipaliwini District, Apalagadi Mounts, 2.17064 N, 56.09961 W, SR140416HC001-23, 16 Apr. 2014, A. Fouquet and J.P. Vacher leg. (NZCS).

\section{Etymology}

Patronymic in honor of Brazilian zoologist Antenor Leitão de Carvalho (1910-1985), who collected the holotype of this species.

\section{Diagnosis}

Spines of ocularium higher than in Amazochroma pedroi gen. et sp. nov. (Fig. 5C); areas II-IV not divided by a median groove (divided in A. pedroi gen. et sp. nov.) (Fig. 5A); area III with a pair of high, paramedian acuminated spines curved backwards (higher than the pair of low, paramedian rounded, tubercles of $A$. pedroi gen. et sp. nov.) (Fig. 5B, D); Cx IV with retrodorsal spiniform apophysis (absent in $A$. pedroi gen. et sp. nov.) (Fig. 5A); Tr IV with prolateral, distal, higher apophysis, forming a bifurcated bar ending in two spines (instead the aborted hook form in A. pedroi gen. et sp. nov.) (Fig. 5A); 
Fe IV without spines, only tubercles (instead of higher spines on the prolateral and retrolateral axes of A. pedroi gen. et sp. nov.) (Fig. 5E-H).

\section{Redescription}

\section{Holotype (male)}

Measurements. CW 3.3, CL 2.0; AW 6.1, AL 3.6. Leg measurements in Table 3, tarsal counts in Table 4.

Dorsum. Dorsal scutum almost as long as wide, abdominal scutum with lateral margins strongly convex, widest at area II and highest at area III (Fig. 5A, D). Carapace with several tubercles on posterior region (Fig. 5A, D). Cheliceral sockets shallow, with a small apophysis in the center. Ocularium elliptical, high, inclined frontwards, placed in middle of carapace, armed with a pair of divergent high spines fused at baseline and inclined frontwards (Fig.5A, C-D). Mesotergum divided into four clearly defined areas. Area I divided into left and right halves by median groove. Area II anterior lateral border invading slightly space of area I and posterior lateral border invading the space of area III. AS lateral borders with tubercles on full extent, gradually growing to height of area III. All areas with many tubercles. Area I with a pair of paramedian tubercles higher than the others. Area II with one main transverse row of tubercles, replaced in middle by two pairs (one anterior and one posterior) of moderate-sized tubercles forming a trapezoid. Besides those, several others minor tubercles. Area III with a pair of high paramedian acuminated spines curved backwards, with the base covered by small tubercles (Fig. 5A-B, D). Area IV with horizontal row of 3 highlighted tubercles. Posterior border of dorsal scutum and free tergites with a horizontal row of tubercles with same height as highlighted on area IV.

VENTER. Cx I-III parallel to each other; each with ventral transverse rows of 9-10 setiferous tubercles (Cx I main row with higher and sharper tubercles). Cx IV much larger than the others, directed obliquely. Stigmatic area Y-shaped, clearly sunken relative to distal part of coxa IV. Intercoxal bridges well marked. Stigmata clearly visible. Free sternites and anal operculum each with a transverse row of small tubercles.

Chelicera. Basichelicerite elongate, bulla well marked, with marginal setiferous tubercles - three ectal, three posterior, one mesal and one dorso-basal; hand not swollen (Fig. 5A).

Pedipalpus. Tr with two dorso-ectal, dorso-mesal and medio-ventral setiferous tubercles. Fe with one meso-distal and one mesal ventro-basal setiferous tubercles. Pa with one meso-distal setiferous tubercle. Ti with two rows of setiferous tubercles; four (IiIi) ventro-mesal and four (Iiii) ventro-ectal, of which the two distal are geminated. Ta with two rows of setiferous tubercles; three (IIi) ventro-mesal and four (IiIi) ventro-ectal.

Legs. Tr I-III each with several ventral tubercles. Fe I and II straight. Fe I retrolateral proximal tubercle higher than the others, not forming a spur. Tr I with prodorsal, proventral, retroventral and retrodorsal rows of small tubercles. Fe II with prodorsal, prolateral, proventral, retroventral, retrolateral and retrodorsal rows of small tubercles. Fe II with a small retrodorsal distal tubercle higher than the others, not forming a spur. Tr II with prodorsal, proventral, retroventral and retrodorsal rows of small tubercles. Fe III substraight. Fe III and Ti III with prodorsal, prolateral, retrolateral and retrodorsal rows of small tubercles, with proventral and retroventral rows of tubercles gradually growing to the distal portion. Fe III and Mt III with a well-developed retrodorsal distal spur. Posterior border of Cx IV not reaching longitudinally the posterior border of dorsal scutum. Cx IV with a prolateral apical caniniform apophysis, moderately elongate and a retrodorsal spiniform apophysis (Fig. 5A). Cx IV with prodorsal, prolateral and proventral rows of tubercles. Tr IV prolaterally with three conical apophyses: two proximal, unequal ones and one distal, longer, bifurcated. Tr IV distally and retrolaterally with one spearhead apophysis. Tr IV ventrally with several tubercles along its entire length. Fe IV substraight, curved from the medial region toward dorsal. Fe IV with prodorsal, prolateral, retroventral and retrodorsal rows of 

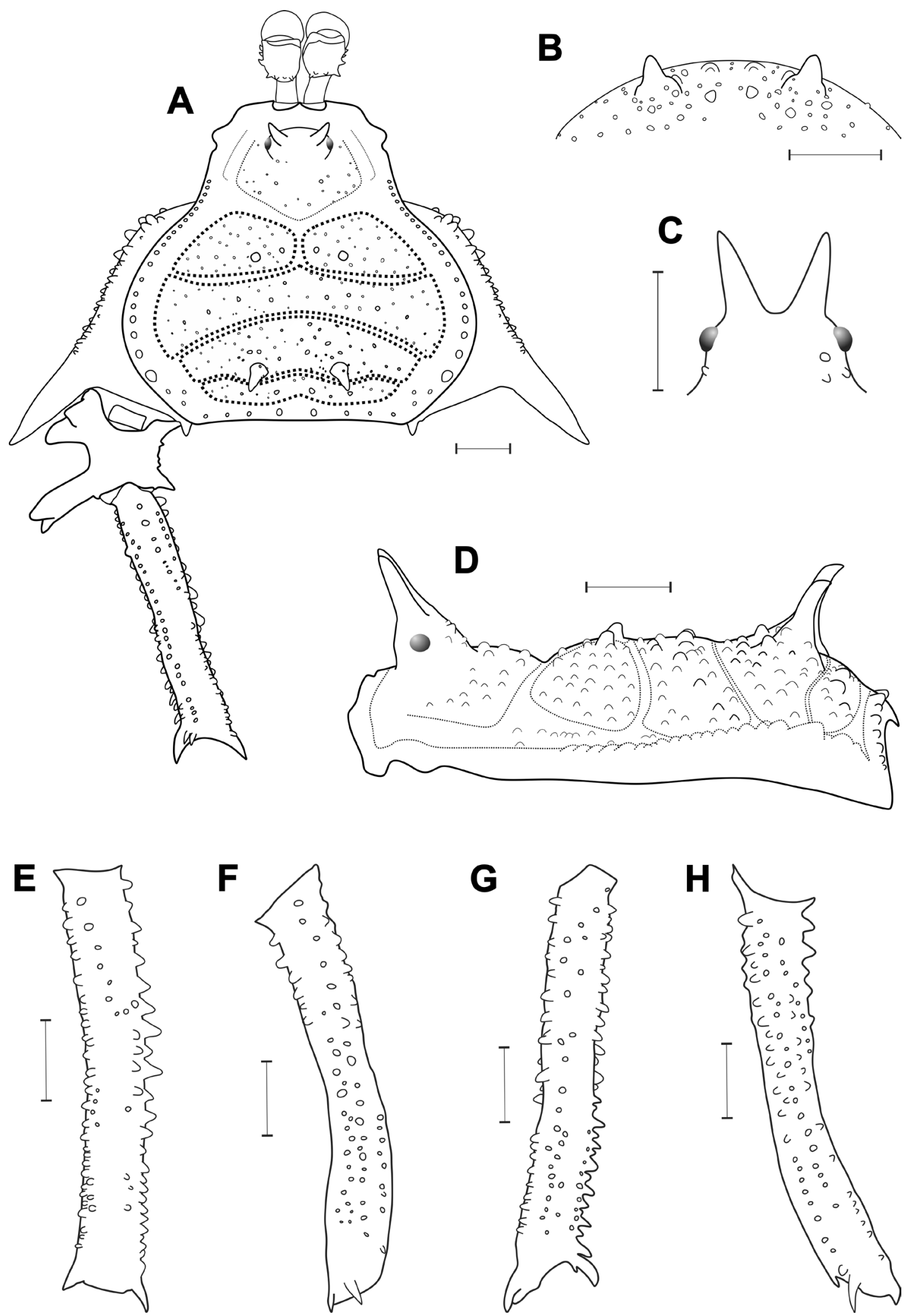

Fig. 5. Amazochroma carvalhoi (Mello-Leitão, 1941) gen. et comb. nov., ふ̂, holotype (MNRJ 5143). A. Habitus, dorsal view. B. Armature of scutal area III, dorso-posterior view. C. Ocularium, frontal view. D. Habitus, lateral view. E. Left femur IV, dorsal view. F. Same, retrolateral view. G. Same, ventral view. H. Same, prolateral view. Scale bars $=1 \mathrm{~mm}$. 
Table 3. Leg measurements (in mm) of Amazochroma carvalhoi (Mello-Leitão, 1941) comb. nov., ô, holotype (MNRJ 5143).

\begin{tabular}{cccccccc}
\hline & $\mathrm{Tr}$ & $\mathrm{Fe}$ & $\mathrm{Pa}$ & $\mathrm{Ti}$ & $\mathrm{Mt}$ & $\mathrm{Ta}$ & Total \\
\hline Leg I & 0.7 & 3.7 & 1.2 & 2.5 & 4.3 & 2.3 & 14.7 \\
Leg II & 0.9 & 7.3 & 2.0 & 5.7 & 7.3 & 4.5 & 27.7 \\
Leg III & 1.4 & 6.3 & 1.8 & 3.7 & 6.8 & 2.9 & 22.9 \\
Leg IV & 2.1 & 6.9 & 2.6 & 6.7 & 11.0 & 3.1 & 32.4 \\
\hline
\end{tabular}

Table 4. Tarsal counts of Amazochroma carvalhoi (Mello-Leitão, 1941) comb. nov., đ̂, holotype and other material examined and Amazochroma pedroi gen. et sp. nov., male holotype and paratypes.

\begin{tabular}{ccccc}
\hline & \multicolumn{2}{c}{ Amazochroma carvalhoi } & \multicolumn{2}{c}{ Amazochroma pedroi } \\
\hline Leg I & $0(\mathrm{n}=5)$ & $\phi(\mathrm{n}=6)$ & $\oint^{\Uparrow}(\mathrm{n}=6)$ & $+(\mathrm{n}=4)$ \\
Leg II & $6(3)$ & $6(3)$ & $6-8(3-4)$ & $6(3)$ \\
Leg III & $8-10(2-3)$ & $8-9(3)$ & $8-11(3-4)$ & $8-9(3)$ \\
Leg IV & 7 & 7 & $7-8$ & 7 \\
\hline
\end{tabular}

small tubercles, dorsal tubercles only in proximal portion (Fig. 5E-H). Fe IV prodorsally (entire length) and retrolaterally (proximal-medial portion) with a row of setiferous tubercles (Fig. 5E-F, H). Fe IV proventrally and retrodorsally with one distal spine forming a spur (Fig. 5E-H). Pa IV covered by tubercles in dorsal view; also with proventral and retroventral rows of three tubercles each. Ti IV with prodorsal, prolateral, proventral, retroventral, retrolateral and retrodorsal rows of tubercles. Ti IV with proventral and retroventral distal spurs. Tarsal counts: 6(3)-6(3)/9(3)-9(3)/7-7/7-7.

PeNIs. VP sharply divided into two regions: distal part rectangular, proximal part elliptical (Fig. 6A-C). Ventral surface of VP entirely covered with microsetae of type 1 (Fig. 6C). All macrosetae inserted on lateral of VP: A1-A3 cylindrical, thick, on basal third of VP, A1 oriented dorsally, A2 oriented sidewards, A3 oriented ventrally (Fig. 6A-E); B1 inserted ventrally, below the line of A3 (Fig. 6C-D); $\mathrm{C} 1-\mathrm{C} 3$ slender, only moderately elongate, forming an almost longitudinal row on the distal part of VP, $\mathrm{C} 1-\mathrm{C} 2$ close together on distal portion, $\mathrm{C} 3$ on medial basal portion (Fig. 6A-E); D1 medium, midway between $\mathrm{C} 3$ and A1 (Fig. 6A-E); E1-E2 inserted ventrally, E1 between the height of C1-C2, E2 beside C3 (Fig. 6C-D). Glans sac long, arising from middle bulge on podium, extended as a dorsal process to height of central sinuosity of stylus (Fig. 6A-B, D-E). Stylus stout, cylindrical and S-curved to dorsal, without any processes (Fig. 6A-B, D-E). Apex of stylus flattened dorsoventrally, with three barbs on each side, one on middle of ventral portion, two on marginal part of medium-basal ventral portion (Fig. 7F-G).

Color (in vivo). Color background of scutum, coxae and trochanters Strong Reddish Brown (40), with spines of ocularium, paramedian tubercles of areas I and III and main apophyses of coxae and trochanter IV Brownish Black (65). Dry marks Very Pale Purplish Blue (202), distributed on Cx and Tr I-IV, free tergites I-III and all over dorsal scutum encircling tubercles, excepted in two crescent-shaped stripes extending from carapace to area III. Chelicerae, pedipalps (glossier than legs) and most of legs I-IV (excepting femora) Strong Yellow (84). Femora 3-banded: basal $40 \%$ as scutum, median $50 \%$ as apophyses and distal $10 \%$ as rest of legs. 

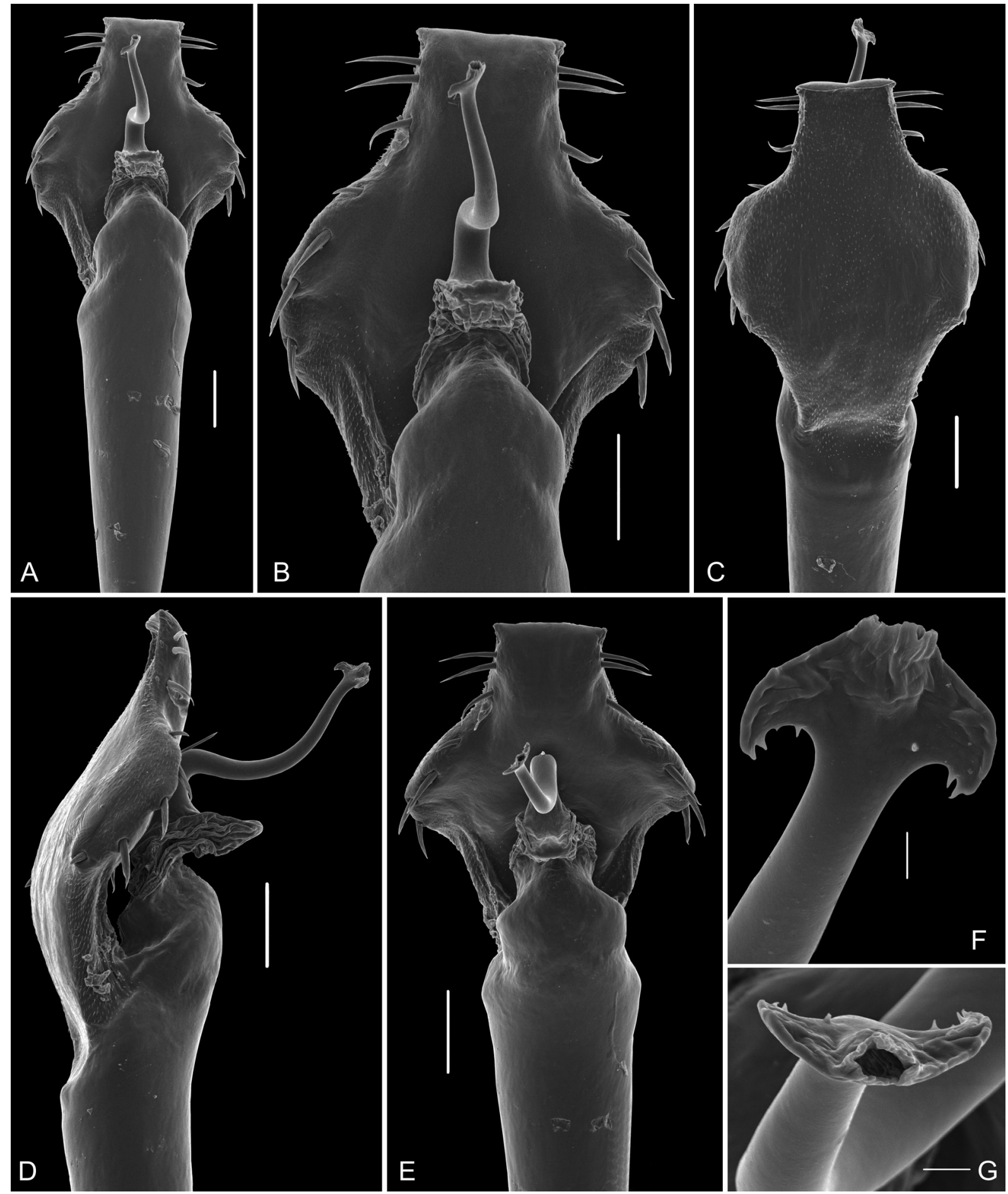

Fig. 6. Amazochroma carvalhoi (Mello-Leitão, 1941) gen. et comb. nov. (MNRJ 8801); đ̂, genitalia, distal part. A. Dorsal view, panoramic. B. Same, greater magnification showing glans. C. Ventral view. D. Lateral view. E. Dorso-apical view. F. Stylus, apex, apical view. G. Same, dorsal view. Scale bars: $\mathrm{A}-\mathrm{E}=100 \mu \mathrm{m} ; \mathrm{F}-\mathrm{G}=10 \mu \mathrm{m}$. 
VARIATION. Besides the variation in tarsal counts, shown in Table 4, the distribution and development of tubercles, apophyses and spines in our sample was fairly uniform. No minor ("beta") males were detected.

\title{
Female (MNRJ 8811)
}

CW 4.2, CL 2.7; AW 7.6, AL 4.7. Cx IV with much weaker armature compared to male, main apophysis reduced to a simple spine. Fe IV thinner, less curved and armed when compared to male. Fe IV with fewer spines on distal proventral axis and a retrolateral distal spur.

\section{Distribution}

BRAZIL, Amazonas (NT 0173 - Uatuma-Trombetas Moist Forests), Mato Grosso (NT 0140 - Mato Grosso Seasonal Forests), Pará (NT 0170 - Tocantins-Pindaré Moist Forests); FRENCH GUIANA, Maripasoula; SURINAME, Sipaliwini (NT 0125 - Guianan Moist Forests) (Fig. 2).

\section{Remarks}

This species was described in Discocyrtus, and never illustrated. In a catalogue of the Pachylinae, Soares \& Soares (1954) merely listed the name. Its generic assignment has never been challenged.

\author{
Amazochroma pedroi gen. et sp. nov. \\ urn:1sid:zoobank.org:act:1E6958EB-B762-4244-B16D-A96EBB853365
}

Figs 1 E-F, 7-9

\section{Material examined}

\section{Holotype}

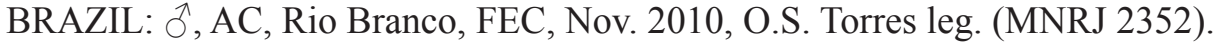

\section{Paratypes}

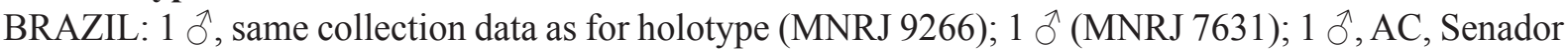
Guiomard, Reserva Extrativista de Catuaba, 2002, E.F. Morato leg. (IBSP 10234); 1 ㅇ, RO, Monte Negro, 22-24 Jul. 2007, P.I. Silva Jr. leg. (MNRJ 9267); 1 ðૈ, 1 \&, RO, Monte Negro, LC12,5 - BR421,

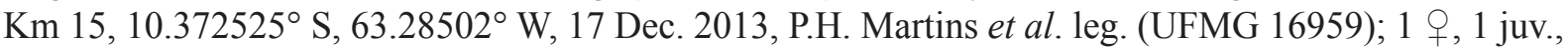
RO, Monte Negro, LC25, Km 10, $10.24694^{\circ}$ S, 63.4046 W, 19 Dec. 2013, Martins, P.H. et al. leg.

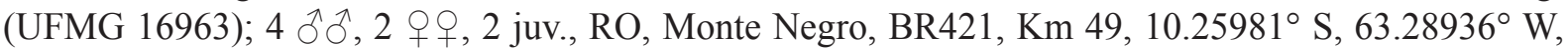

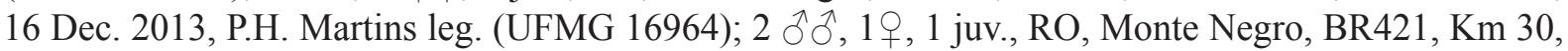
$10.1164^{\circ} \mathrm{S}, 63.230861^{\circ} \mathrm{W}, 18$ Dec. 2013, P.H. Martins et al. leg. (UFMG 16968); 1 ô, 2 우, RO, Porto Velho, Apr. 1996, Team IBSP/SMNK leg. (IBSP 0936).

\section{Etymology}

The species name honors our friend, the arachnologist Pedro Henrique Martins, who collected most of the type series and provided fine pictures of this species.

\section{Diagnosis}

Carapace with a pair of paramedian larger tubercles, as large as found at paramedian of area I, darker, contrasting with background (absent in A. carvalhoi comb. nov.) (Fig. 7A, D); areas I-III with two higher tubercles next to the median groove (absent in A. carvalhoi comb. nov.) (Fig. 7A); area III with a pair of low, paramedian, rounded tubercles (lower and broader than the pair of high, paramedian, acuminated spines of $A$. carvalhoi comb. nov.) (Fig. 7B, D); Tr IV prolateral median with an apophysis (not occurring in A. carvalhoi comb. nov.) (Fig. 7A); Fe IV prolaterally and retrolaterally with high spines (instead of spines absent in A. carvalhoi comb. nov.) (Fig. 7F, H). 

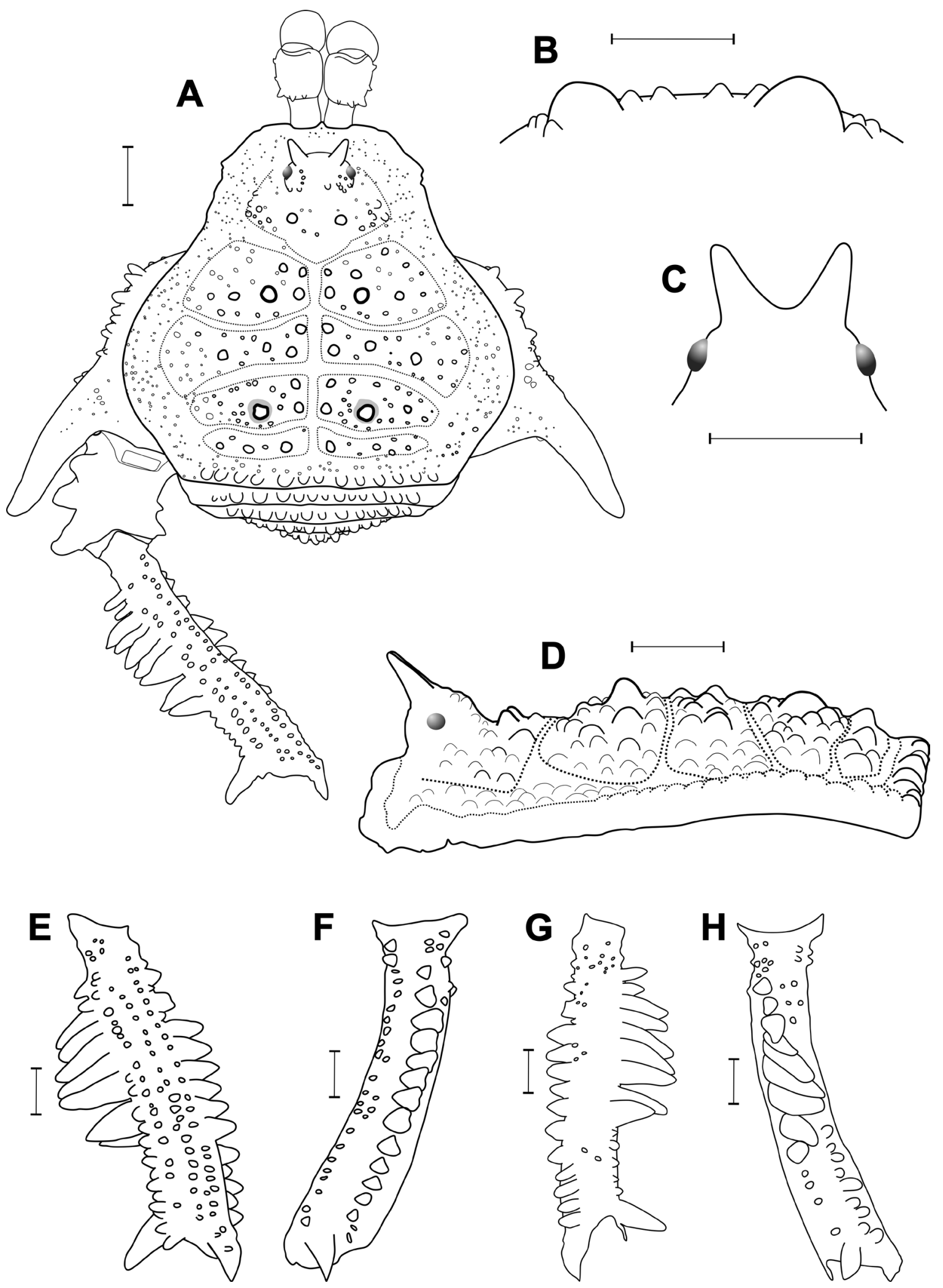

Fig. 7. Amazochroma pedroi gen. et sp. nov., ô, holotype (MNRJ 2352). A. Habitus, dorsal view. B. Armature of scutal area III, posterior view. C. Ocularium, frontal view. D. Habitus, lateral view. E. Left femur IV, dorsal view. F. Same, retrolateral view. G. Same, ventral view. H. Same, prolateral view. Scale bars $=1 \mathrm{~mm}$. 


\section{Description}

Male (holotype)

CW 3.7, CL 2.4; AW 6.9, AL 3.9. Leg measurements in Table 5, tarsal counts in Table 4.

Dorsum. Dorsal scutum almost as long as wide, abdominal scutum with lateral margins strongly convex, widest at area II and highest at area III (Fig. 7A, D). Carapace with several tubercles on posterior region, with a pair of paramedian larger tubercles, darker, contrasting with background (Fig. 7A, D). Cheliceral sockets shallow, with a small apophysis in center. Ocularium elliptical, high, inclined frontwards, placed in middle of carapace, armed with a pair of divergent high spines fused at baseline and inclined frontwards (Fig. 7A, C-D). Mesotergum divided into four clearly defined areas. Areas I, III and IV divided into left and right halves by median groove. Area II anterior lateral border invading slightly space of area I and posterior lateral border gently invading space of area III. AS lateral borders with ordinary tubercles on full extent. All areas with several tubercles (darker than background). Area I with a pair of paramedian tubercles higher than the others and two medium tubercles (one anterior and one posterior) highlighted next to median groove. Area II with two medium tubercles (one anterior and one posterior) highlighted next to median groove and two medium tubercles highlighted abreast on horizontal medium. Area III with a pair of low, paramedian, rounded tubercles and two medium tubercles (one anterior and one posterior, about half size of paramedian) highlighted next to median groove (Fig. 7A-B, D). Area IV with six to eight minor tubercles plus horizontal row of three rounded, larger tubercles on each side. Posterior border of dorsal scutum and free tergites with a horizontal row of rounded tubercles.

VENTER. Cx I-III parallel to each other; each with ventral transverse rows of 6-10 setiferous tubercles (Cx I main row with higher and sharper tubercles). Cx IV much larger than the others, directed obliquely. Stigmatic area Y-shaped, clearly sunken relative to distal part of coxa IV. Intercoxal bridges well marked. Stigmata clearly visible. Free sternites and anal operculum each with one transverse row of small tubercles.

Chelicera. Basichelicerite elongate, bulla well marked, with marginal setiferous tubercles - three ectal, three posterior, one mesal; hand not swollen (Fig. 7A).

PedipalPus. Tr with three dorso-median rounded tubercles in a median elevation and two ventro-median setiferous tubercle (mesal highest in comparison to median). Fe with one meso-distal and one mesal, ventro-basal setiferous tubercles. Pa unarmed. Ti with two rows of setiferous tubercles; four (IiIi) ventromesal and four (IiIi) ventro-ectal, of which the two distal are geminated. Ta with two rows of setiferous tubercles; three (IIi) ventro-mesal and four (IiIi) ventro-ectal.

Legs:. Tr I-III each with several ventral tubercles. Fe I-III slightly sinuous. Fe I and Ti I with prodorsal, prolateral, proventral, retroventral, retrolateral and retrodorsal rows of small tubercles. Fe II with a little retrodorsal distal tubercle, not forming a spur. Fe II and Ti II with prodorsal, proventral, retroventral and retrodorsal rows of small tubercles. Fe III substraight. Fe III and Ti III with prodorsal and retrodorsal rows of small tubercles and proventral and retroventral rows of acuminated tubercles. Fe III and Mt III with a well-developed retrodorsal, distal spur. Posterior border of Cx IV not reaching posterior border of dorsal scutum longitudinally. Cx IV with a prolateral apical caniniform apophysis, moderately elongate (Fig. 7A). Cx IV with prolateral, proventral, ventral and retrolateral rows of tubercles. Tr IV with two distal, retrolateral spines (ii). Tr IV median proventrally with one broad spearhead apophysis. Tr IV ventrally with several tubercles along its entire length. Tr IV prolaterally with three broad, conical apophyses. Fe IV substraight, curved from medial region toward retrolateral. Fe IV with dorsal, retrodorsal row of small tubercles (Fig. 7E-F). Fe IV with medial-distal, prodorsal row of rounded tubercles (Fig. 7E, H); Fe IV with proximal-medial, prolateral row of nine conical and substraight spines and a large, conical spine on distal region (Fig. 7H). Fe IV with seven medial, retrolateral higher 


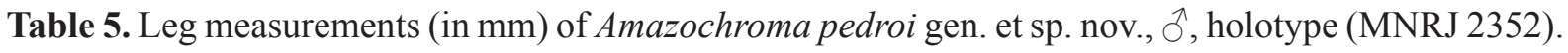

\begin{tabular}{cccccccc}
\hline & $\mathrm{Tr}$ & $\mathrm{Fe}$ & $\mathrm{Pa}$ & $\mathrm{Ti}$ & $\mathrm{Mt}$ & $\mathrm{Ta}$ & Total \\
\hline Leg I & 0.6 & 2.5 & 1.1 & 1.8 & 3.1 & 1.9 & 11.0 \\
Leg II & 0.9 & 5.5 & 1.5 & 4.5 & 6.1 & 3.3 & 21.8 \\
Leg III & 1.0 & 4.2 & 1.6 & 3.0 & 4.7 & 2.0 & 16.5 \\
Leg IV & 1.6 & 5.1 & 1.8 & 4.1 & 7.5 & 2.2 & 22.3 \\
\hline
\end{tabular}

acuminated spines followed by four smaller, acuminated tubercles on distal region (Fig. 7F); Fe IV with small distal, retrodorsal spur (Fig. 7E-F); Fe IV with proventral, ventral and retroventral diffuse tubercles. $\mathrm{Pa} I V$ covered by tubercles in dorsal view. Pa IV with proventral and retroventral, medial-distal row of three acuminate tubercles. Ti IV with prodorsal, prolateral, proventral, retroventral and retrodorsal rows of acuminate tubercles. Ti IV with proventral and retroventral, distal spur. Tarsal counts: 6(3)-6(3)/?$8(3) / 7-7 / 7-7$.

PENIS. VP divided into two regions: distal part rectangular, proximal part trapezoidal (Fig. 8A-C). Ventral surface of VP entirely covered with microsetae of type 1 (Fig. 8C, 9B). All macrosetae inserted on lateral of VP: A1-A3, cylindrical, thick, on basal third of VP, A1 oriented dorsally, A2 oriented sidewards, A3 oriented ventrally (Fig. 8A-C); B1 inserted ventrally, below the line of A3 (Fig. 8C); $\mathrm{C} 1-\mathrm{C} 3$ slender, only moderately elongate, forming a row on the distal part of VP, C1-C2 close together on the distal portion, $\mathrm{C} 3$ on medial basal portion (Figs 8A-C, 9B); D1 medium, midway between $\mathrm{C} 3$ and A1 (Figs 8A-C, 9B); E1-E2 inserted ventrally, E1 between the height of C1-C2, E2 slightly below C3 (Figs 8B, 9B). Glans sac short, arising from middle bulge on podium, not extended as a dorsal process
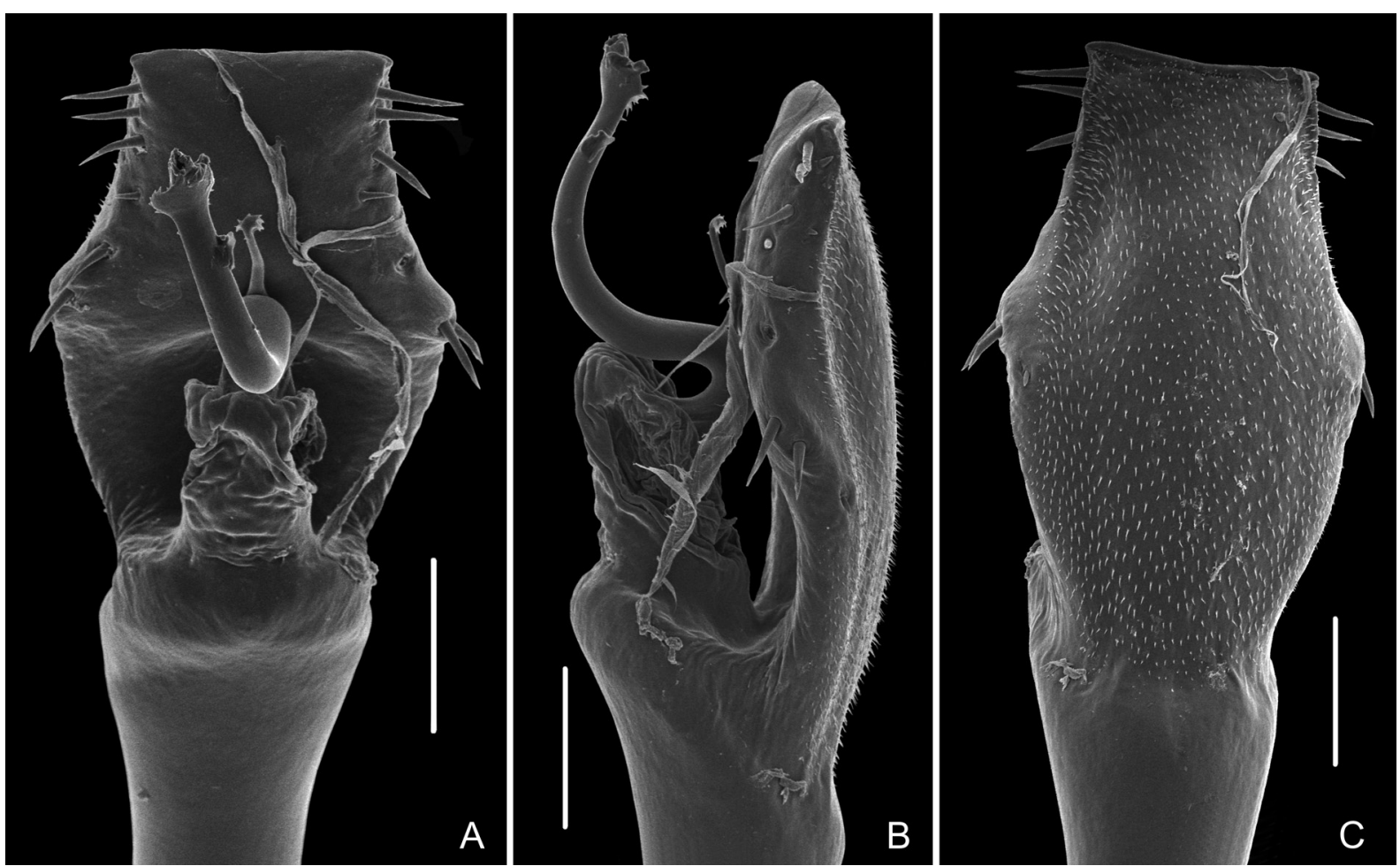

Fig. 8. Amazochroma pedroi gen. et sp. nov. (MNRJ 2352). đ, genitalia, distal part. A. Dorsal view. B. Lateral view. C. Ventral view. Scale bars $=100 \mu \mathrm{m}$. 

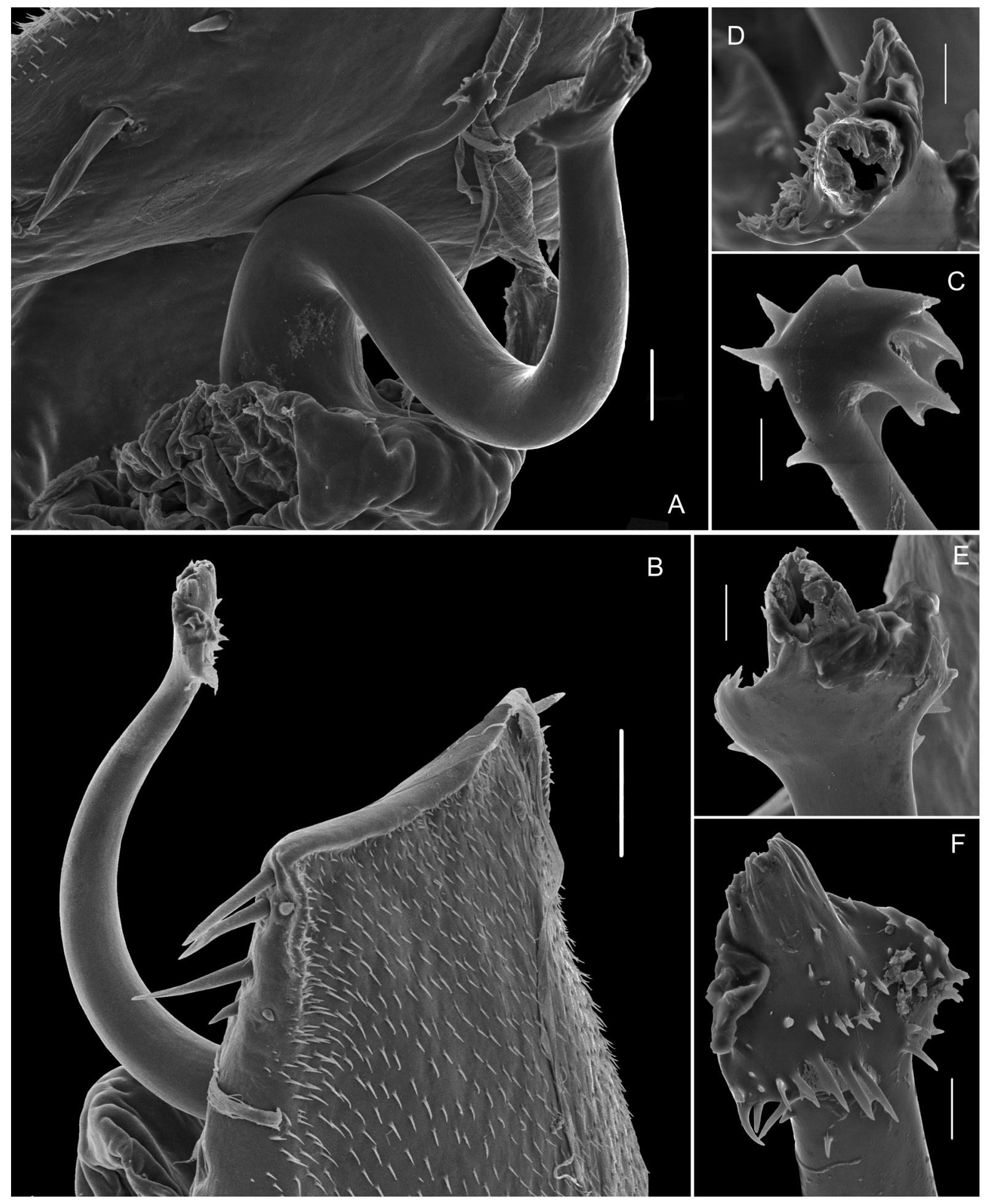

Fig. 9. Amazochroma pedroi gen. et sp. nov. (MNRJ 2352). Oૈ, genitalia, diverse details. A. Stylus, dorso-lateral view, showing stunted ventral process and small flabellum. B. Lateral view, also showing apex of ventral plate. C. Flabellum of ventral process, dorso-apical view. D. Stylus, apex, dorsal view. E. Same, apical view. F. Same, posterior view. Scale bars: $A=20 \mu \mathrm{m} ; \mathrm{B}=50 \mu \mathrm{m} ; \mathrm{D}-\mathrm{F}=10 \mu \mathrm{m}$; $\mathrm{C}=5 \mu \mathrm{m}$. 
CARVALHO R.N. \& KURY A.B., New subfamily of Gonyleptidae
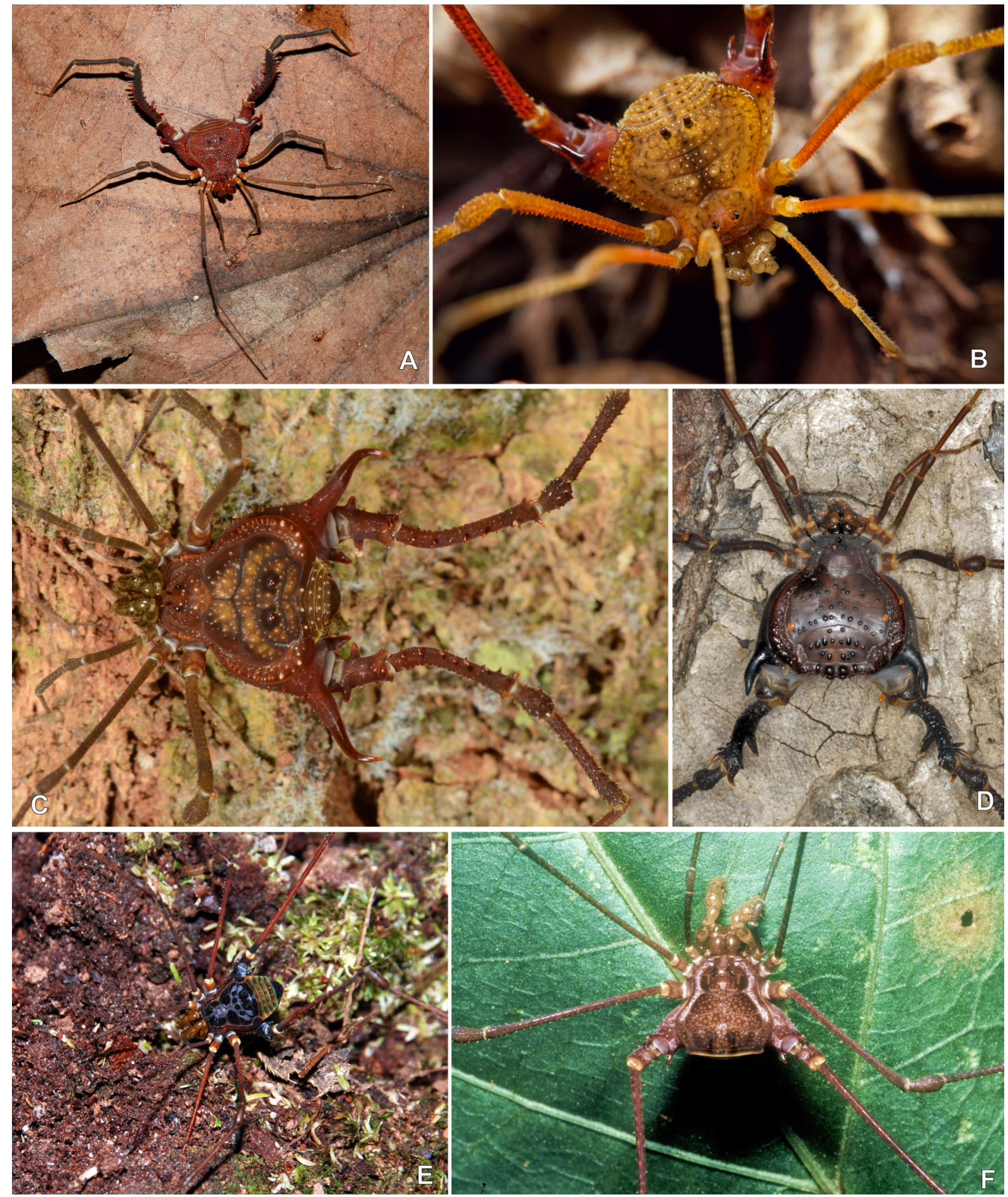

Fig. 10. Male specimens of Discocyrtus, ex-Discocyrtus, Mitobatinae, ex-Mitobatinae, Pachylinae and ex-Pachylinae, in vivo. - Roeweriinae. A. Discocyrtanus pertenuis (Mello-Leitão, 1935), Brazil, Minas Gerais, Belo Horizonte. B. Roeweria virescens (Mello-Leitão, 1940), Brazil, São Paulo, Piedade. "Pachylinae". C. Discocyrtus crenulatus Roewer, 1913, Brazil, Rio de Janeiro, Taquara. - Pachylinae. D. Pachylus chilensis (Gray, 1833), Chile.- Mitoblatinae. E. Discocyrtoides nigricans (Mello-Leitão, 1922), Brazil, Minas Gerais, Ouro Preto, and F. Longiperna concolor (Mello-Leitão, 1923), Brazil, São Paulo, Ubatuba. Images courtesy Arthur Anker \& Pedro Martins (A, C, E), João Burini (B), Ricardo Pinto-da-Rocha (D) and Glauco Machado (F). 
(Figs 8A-B, 9A). Stylus stout, cylindrical and S-shaped curved to dorsal (Figs 8A-B, 9A-B). Apex of stylus flattened dorsoventrally, covered by spines ventrally (Fig. 10B, D-F). Ventral process of stylus gently curved, with half longitudinal length of stylus (Figs 8A-B, 9A, C). Apex of ventral process of stylus forming a small flabellum with flaps deeply serrated (Fig. 9A, C).

Color (in vivo). Color background of scutum and coxae Deep Red (13), with paramedian tubercles of areas I and III Very Dark Red (17). Dry marks Very Pale Purplish Blue (202) distributed on Cx IV, free tergites I-III and uniformly all over dorsal scutum encircling the tubercles; also appearing faintly on basal parts of legs I-IV. Chelicerae, pedipalps (glossier than legs) and trochanters I to IV and base (proximal 15\%) of femora III-IV Deep Orange (51). Femora and tibiae III and IV mostly (medial 70\% of femur) Blackish Red (21). Distal 15\% of femora III-IV and patellae III-IV Strong Orange (50). Tibiae III-IV repeating the color of femora, without lighter detail at base. Metatarsi and tarsi III-IV Brownish Orange (54). Legs I and II similar to posterior ones, but with colors much attenuated.

VARIATION. Besides the variation in tarsal counts, shown in Table 4, the minor ("beta") males only show a difference in attenuated armature of Fe IV proventral and retrolateral rows of spines. Distribution and development of tubercles and apophyses in our sample fairly uniform.

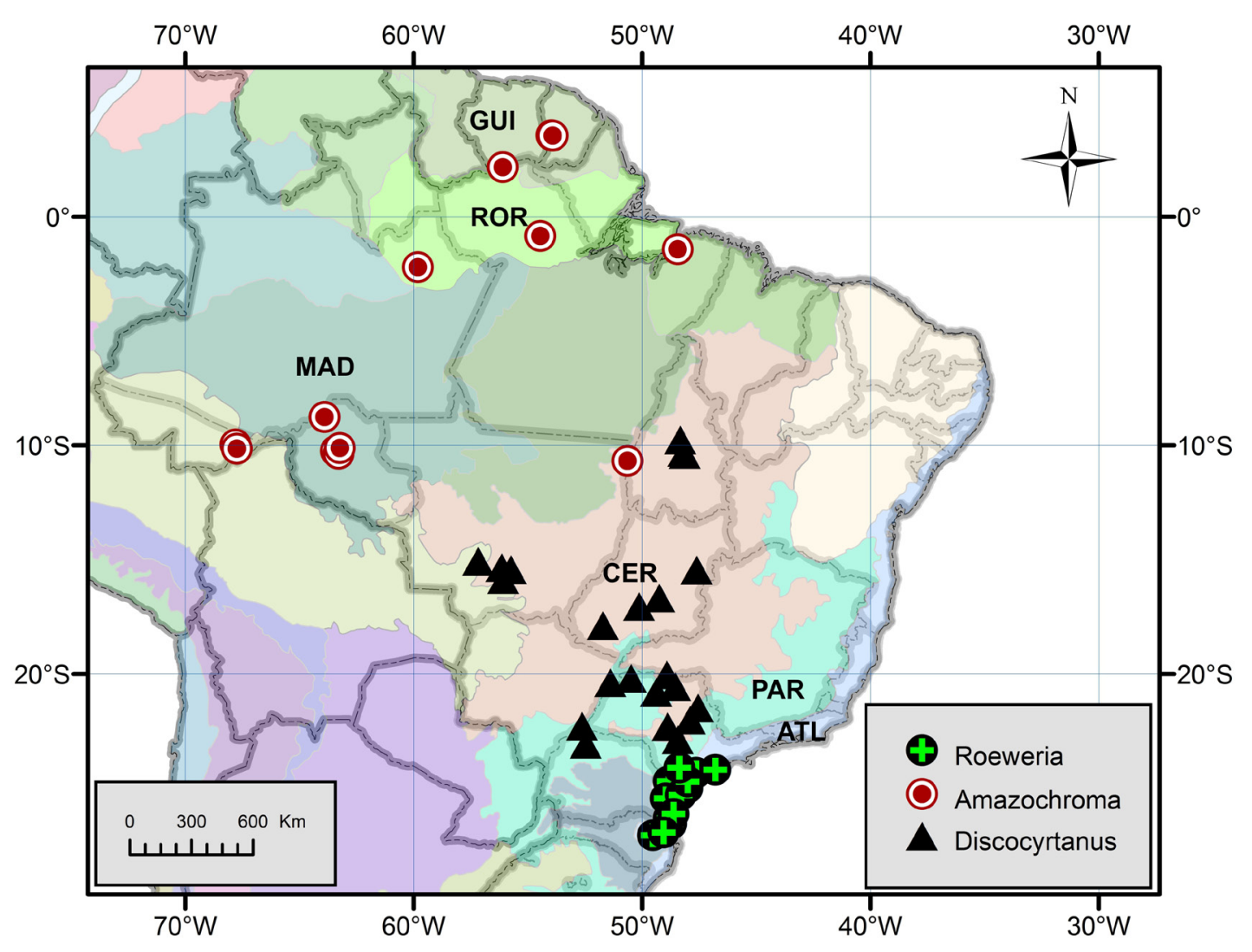

Fig. 11. Brazil and Guianas, showing parapatric distribution of the genera of Roeweriinae subfam. nov. Shaded areas in the background are Morrone's regionalization of the Neotropics ("provinces"; Morrone, 2014). $\mathrm{ATL}=$ Atlantic province; $\mathrm{CER}=$ Cerrado province; $\mathrm{GUI}=$ Guianan Lowlands province; $\mathrm{MAD}=$ Madeira province; $\mathrm{PAR}=$ Paraná Forest province; $\mathrm{ROR}=$ Roraima province. 
Female (paratype, MNRJ 9267)

CW 4.2, CL 2.5; AW 7.4, AL 4.6. Cx IV with much weaker armature, main apophysis reduced to a simple spine. Fe IV thinner and less curved when compared to that of male. Fe IV with fewer spines on distal proventral axis and a retrolateral distal spur.

\section{Distribution}

BRAZIL, Acre (NT 0166 - Southwest Amazon Moist Forests) and Rondônia (NT 0135 - MadeiraTapajós Moist Forests). (Fig. 2).

\section{Discussion}

In the present study, we obtained evidence for a monophyletic group here nicknamed DRMN (that is, Discocyrtus, Roeweriinae subfam. nov., Mitobatinae and Neopachylus; Fig. 4). Inside DRMN we detected for the first time a group formed by "false" Discocyrtus (Amazochroma gen. nov. and Discocyrtanus) and Roeweria (a genus which has wandered through many affiliations), which we described above as the new subfamily Roeweriinae subfam. nov. The parapatric distribution of the genera of Roeweriinae subfam. nov. in South America is illustrated in Figs 2 and 11. Amazochroma gen. nov. occurs in the upper and lower Amazon drainage (provinces Madeira, Pará, Rondônia, Roraima and Xingu-Tapajós, corresponding to various WWF ecoregions of biome 01, Tropical/Subtropical Moist Broadleaf Forests), while Discocyrtanus is basically distributed in the Cerrado Province (Morrone 2014), which corresponds to WWF NT 0704 (Cerrado, belonging to biome 07, Tropical/Subtropical Grasslands, Savannas, Shrublands) but also occurring in fringes of the Morrone's Paraná Forest Province, which is equivalent to ecoregion NT 0150 (Alto Paraná Atlantic Forests). Roeweria is mostly endemic to the Atlantic Province, with a marginal incursion into the Paraná Forest Province.

Discocyrtanus, Discocyrtus, Neopachylus and Roeweria were previously allocated to the nonmonophyletic Pachylinae, but our analysis confirmed the modern trend of shrinking the circumscription of the Pachylinae to the genera in the most immediate vicinity of Pachylus C.L. Koch, 1839, while the above cited groups are here hypothesized to be closest to the Mitobatinae, a subfamily distributed from the Brazilian Atlantic Forest.

The Mitobatinae gradually specialized into a new ecological niche: they abandoned life in the leaf mold and traded leg armature for elongation, the Cx IV musculature was greatly reduced, losing the typical gonyleptid armature, which even influenced the body outline, which changed from pyriform in Discocyrtoides to rectangular in Mitobates. Even the microhabitat was modified, with the exchange of ground substrate for massive boulders on water streams. However, closer study of Mitobatinae (especially the early derivative species) still betrays an obvious connection with Discocyrtus and the like.

Earlier authors have not always understood the relationships of Mitobatinae, ascribing to this subfamily virtually every long-legged species of Grassatores. Yet, short-legged Laniatores such as Discocyrtus and immediately related genera (Fig. 10) have long since been thought to be more closely related to the Mitobatinae than to the Pachylinae. However, a recent analysis (Bragagnolo \& Pinto-da-Rocha 2012) placed Discocyrtus testudineus very far away from the Mitobatinae, together with the Caelopyginae, a result at odds with our present concept of DRMN. Mello-Leitão (1923) came up with the concept of the Bourguyiinae, which at one point included Discocyrtoides - and even this name per se betrayed a perception of the proximity with Discocyrtus. Roeweria was originally included in Mitobatinae, one of its species was originally included in Discocyrtus, and one of its synonyms was even synonymized under Discocyrtus, not to mention its synonymy under Discocyrtoides. 
More recently, Kury (1991) indicated Discocyrtus as the possible sister-group of the Mitobatinae, and Pinto-da-Rocha et al. (2014) obtained a tree where both Discocyrtus (s. lat.) and Roeweria form a clade with the Mitobatinae. Another interesting possibility raised by molecular studies (Pinto-da-Rocha et al. 2014) is the non-monophyly of the Mitobatinae. At this stage, an increased sampling of nominal Discocyrtus and Mitobatinae is needed to study this hypothesis. That is why we chose here not to ascribe Discocyrtus to any subfamily in Gonyleptidae: an ongoing project is gradually surveying a much denser taxonomic sample of Discocyrtus and other potential disruptors of DRMN monophyly.

\section{Acknowledgements}

This study has been supported by grant \# 562149/2010-4 (PROTAX - OPESC project) and scholarship \# 302116/2010-9 (PQ - AMMA project) from the Conselho Nacional de Desenvolvimento Científico e Tecnológico (CNPq) to ABK and scholarship \# 134421/2016-7 (CNPq) to RNC. The SEM micrographs were taken in the Center for Scanning Electron Microscopy of Museu Nacional/UFRJ (financed by Petrobas), with the kind assistance of Camila Messias. We wish to thank Sébastien Cally \& Jerôme Murienne for placing material of $D$. carvalhoi at our disposal. Their work has benefited from an "Investissement d'Avenir" grant managed by Agence Nationale de la Recherche (CEBA, ref. ANR-10LABX-25-01). We are deeply grateful to P. Ouboter, R. Jairam, V. Kadosoe and A. Gangadin (National Zoological Collection of Suriname) for logistical support, contribution to field work and permit issuing in Suriname. Many thanks are due to Osmar Torres (FEC), Rogério Bertani (IBSP) for the donation and Adalberto Santos (UFMG) for the loan of specimens of $A$. pedroi gen. et sp. nov. Glauco Machado (USP), Sébastien Cally (Université Toulouse III), Paul Sabatier, Pedro Martins (UFMG) and Ricardo Pinto-da-Rocha (USP) kindly contributed pictures of living specimens. The initial version of manuscript benefitted from the criticism of Amanda C. Mendes and of an unknown referee.

\section{References}

Avram Ş. 1968. Laniatores cavernicoles de Roumanie. Révision des genres Scotolemops Rwr., Brigestus Rwr. et Bukowina Rwr. (Opiliones, Phalangodidae). Annales de Spéléologie, 23 (3): 641-665.

Bragagnolo C. \& Pinto-da-Rocha R. 2012. Systematic review of Promitobates Roewer, 1913 and cladistic analysis of Mitobatinae Simon, 1879 (Arachnida: Opiliones: Gonyleptidae). Zootaxa 3308: $1-48$.

Bremer K. 1994. Branch support and tree stability. Cladistics, 10: 295-304. https://doi.org/10.1111/j.1096-0031.1994.tb00179.x

DaSilva M.B. \& Gnaspini P. 2010. A systematic revision of Goniosomatinae (Arachnida: Opiliones: Gonyleptidae), with a cladistic analysis and biogeographical notes. Invertebrate Systematics, 23 (6): 530-624. https://doi.org/10.1071/IS09022

Goloboff P.A. 1993. Estimating character weights during tree search. Cladistics, 9: 83-91.

https://doi.org/10.1111/j.1096-0031.1993.tb00209.x

Goloboff P., Farris J., Källersjö M., Oxelmann B., Ramírez M. \& Szumik C., 2003. Improvements to resampling measures of group support. Cladistics, 19: 324-332.

Goloboff P.A., Carpenter J.M., Arias J.S. \& Esquivel D.R.M. 2008a. Weighting against homoplasy improves phylogenetic analysis of morphological data sets. Cladistics, 24 (5): 758-773. https://doi.org/10.1111/j.1096-0031.2008.00209.x

Goloboff P.A, Farris J.S. \& Nixon K.C. 2008b. TNT, a free program for phylogenetic analysis. Cladistics, 24: 774-786. https://doi.org/10.1111/j.1096-0031.2008.00217.x 
Henriksen K.L. 1932. Descriptiones Laniatorum (Arachnidorum Opilionum Subordinis) fecit William Sørensen. Opus posthumum recognovit et edidit Kai L. Henriksen. Det Kongelige Danske Videnskabernes Selskabs Skrifter Naturvidenskabelig og Mathematisk Afdeling series 9, 3 (4): 197-422.

Jaffer A. 2001+. NBS/ISCC Centroids. In: Color-Name Dictionaries [online].

Available from http://people.csail.mit.edu/jaffer/Color/Dictionaries\#nbs-iscc [accessed 12 Jan. 2017].

Kury A.B. 1989. Notes on Mitobatinae III: A remarkable new Brazilian species of Mitobates Sundevall, 1833 (Opiliones, Laniatores, Gonyleptidae). Boletim do Museu Nacional, (N.S. Zoologia) 328: 1-12.

Kury A.B. 1991. Análise filogenética de Mitobatinae (Opiliones, Laniatores, Gonyleptidae). MSc dissertation, UFRJ/Museu Nacional - Programa de Pós-graduação em Ciências Biológicas (Zoologia). Rio de Janeiro.

Kury A.B. 2003. Annotated catalogue of the Laniatores of the New World (Arachnida, Opiliones). Revista Ibérica de Aracnología volumen. Especial Monográfico 1: 1-337.

Kury A.B. 2008. Two new troglomorph Pachylinae (Opiliones, Laniatores, Gonyleptidae) from caves in Bahia, Brazil. Studies on Neotropical Fauna and Environment 43 (3): 247-253. https://doi.org/10.1080/01650520701731794

Kury A.B. 2016. A classification of the penial microsetae of Gonyleptoidea (Opiliones: Laniatores). Zootaxa 4179 (1): 144-150. https://doi.org/10.11646/zootaxa.4179.1.13

Kury A.B. \& Carvalho R.N. 2016. Revalidation of the Brazilian genus Discocyrtanus, with description of two new species (Opiliones: Gonyleptidae: Pachylinae). Zootaxa 4111 (2): 126-144. https://doi.org/10.11646/zootaxa.4111.2.2

Kury A. \& Medrano M. 2016. Review of terminology for the outline of dorsal scutum in Laniatores (Arachnida, Opiliones). Zootaxa 4097 (1): 130-134. https://doi.org/10.11646/zootaxa.4097.1.9

Kury A.B. \& Orrico V.G.D. 2006. A new species of Lacronia Strand, 1942 from the highlands of Rio de Janeiro (Opiliones, Gonyleptidae, Pachylinae). Revista Ibérica de Aracnologia 13: 147-153.

Kury A.B. \& Villarreal M.O. 2015. The prickly blade mapped: establishing homologies and a chaetotaxy for macrosetae of penis ventral plate in Gonyleptoidea (Arachnida, Opiliones, Laniatores). Zoological Journal of the Linnean Society 174 (1): 1-46. https://doi.org/10.1111/zoj.12225

Löwenberg-Neto P. 2014. Neotropical region: a shapefile of Morrone's (2014) biogeographical regionalisation. Zootaxa, 3802: 300. https://doi.org/10.11646/zootaxa.3802.2.12

Mello-Leitão C.F. de 1923. Opiliones Laniatores do Brasil. Archivos do Museu Nacional 24: 107-197.

Mello-Leitão C.F. de 1930. Nota sobre arachnideos argentinos. I. Ainda o genero Apembolephaenus. II. Um genero e tres especies novas de Gonyleptidas. Annais da Academia Brasileira de Sciencias 2 (4): 211-214.

Mello-Leitão C.F. de 1939. Dois gêneros e sete espécies de Goniléptidas sulamericanos. Boletim Biológico, (N. Série) 4 (3): 345-351.

Mello-Leitão C.F. de 1941. Opiliões coligidos por Antenor Leitão de Carvalho no Tapirapés. Revista Brasileira de Biologia 1 (4): 435-442.

Morrone J.J. 2014. Biogeographical regionalisation of the Neotropical region. Zootaxa 3782 (1): 1-110. https://doi.org/10.11646/zootaxa.3782.1.1

O’Leary M.A. \& Kaufman, S.G. 2012. MorphoBank 3.0: Web application for morphological phylogenetics and taxonomy. Available from http://www.morphobank.org [accessed 05 Mar. 2017]. 
Olson D.M., Dinerstein E., Wikramanayake E.D., Burgess N.D., Powell G.V.N., Underwood E.C., D’Amico J.A., Itoua I., Strand H.E., Morrison J.C., Loucks C.J., Allnutt T.F., Ricketts T.H., Kura Y., Lamoreux J.F., Wettengel W.W., Hedao P. \& Kassem K.R. 2001. Terrestrial ecoregions of the World: A new map of life on Earth. BioScience 51: 933-938.

Pinto-da-Rocha R. 2002. Systematic review and cladistic analysis of the Caelopyginae (Opiliones, Gonyleptidae). Arquivos de Zoologia 36 (4): 357-464.

Pinto-da-Rocha R., Bragagnolo C., Marques F.P.L. \& Antunes Jr M. 2014. Phylogeny of harvestmen family Gonyleptidae inferred from a multilocus approach (Arachnida: Opiliones). Cladistics 30 (5): 519-539. https://doi.org/10.1111/cla.12065

Roewer C.F. 1913. Die Familie der Gonyleptiden der Opiliones-Laniatores. Archiv für Naturgeschichte 79 (4): 1-256.

Roewer C.F. 1923. Die Weberknechte der Erde. Systematische Bearbeitung der bisher bekannten Opiliones. Gustav Fischer, Jena.

Soares B.A.M. \& Soares H.E.M. 1954. Monografia dos gêneros de opiliões neotrópicos III. Arquivos de Zoologia do Estado de São Paulo 8 (9): 225-302.

Soares B.A.M. \& Soares H.E.M. 1970. Opiliões de Itatiaia. Revista Brasileira de Biologia 30 (3): 339350.

Tavares M.L.R. 1981. Descrição de uma nova espécie de Discocyrtus Holmberg, 1878 do estado do Rio Grande do Sul (Opiliones: Gonyleptidae: Pachylinae). Iheringia (Zool.) 60: 55-61.

Manuscript received: 2 February 2016

Manuscript accepted: 5 April 2016

Published on: 9 January 2018

Topic editor: Rudy Jocqué

Section editor: Kurt Jordaens

Desk editor: Jeroen Venderickx

Printed versions of all papers are also deposited in the libraries of the institutes that are members of the EJT consortium: Muséum national d'Histoire naturelle, Paris, France; Botanic Garden Meise, Belgium; Royal Museum for Central Africa, Tervuren, Belgium; Natural History Museum, London, United Kingdom; Royal Belgian Institute of Natural Sciences, Brussels, Belgium; Natural History Museum of Denmark, Copenhagen, Denmark; Naturalis Biodiversity Center, Leiden, the Netherlands; Museo Nacional de Ciencias Naturales-CSIC, Madrid, Spain; Real Jardín Botánico de Madrid CSIC, Madrid, Spain. 